\title{
Neuro-Cognitive Effects of Acute Tyrosine Administration on Reactive and Proactive Response Inhibition in Healthy Older Adults
}

\author{
[Dirjam Bloemendaal, ${ }^{1, \#}$ Monja Isabel Froböse, ${ }^{1}$ [D Joost Wegman, ${ }^{1}{ }^{\circledR}$ Bram Bastiaan Zandbelt, ${ }^{1}$ \\ () Ondine van de Rest, ${ }^{3}{ }^{-}$Roshan Cools, ${ }^{1,2}$ and Esther Aarts ${ }^{1}$
}

\author{
DOI:http://dx.doi.org/10.1523/ENEURO.0035-17.2018
}

${ }^{1}$ Donders Institute for Brain, Cognition and Behaviour, Centre for Cognitive Neuroimaging, Radboud University, Nijmegen 6525EN, The Netherlands, ${ }^{2}$ Department of Psychiatry, Radboud University Medical Center, Nijmegen 6500HB, The Netherlands, and ${ }^{3}$ Division of Human Nutrition, Wageningen University, Wageningen 6700AA, The Netherlands

\begin{abstract}
The aging brain is characterized by altered dopamine signaling. The amino acid tyrosine, a catecholamine precursor, is known to improve cognitive performance in young adults, especially during high environmental demands. Tyrosine administration might also affect catecholamine transmission in the aging brain, thereby improving cognitive functioning. In healthy older adults, impairments have been demonstrated in two forms of response inhibition: reactive inhibition (outright stopping) and proactive inhibition (anticipatory response slowing) under high information load. However, no study has directly compared the effects of a catecholamine precursor on reactive and load-dependent proactive inhibition. In this study we explored the effects of tyrosine on reactive and proactive response inhibition and signal in dopaminergically innervated fronto-striatal regions. Depending on age, tyrosine might lead to beneficial or detrimental neurocognitive effects. We aimed to address these hypotheses in 24 healthy older human adults (aged 61-72 years) using fMRI in a double blind, counterbalanced, placebo-controlled, within-subject design. Across the group, tyrosine did not alter reactive or proactive inhibition behaviorally but did increase fronto-parietal proactive inhibition-related activation. When taking age into account, tyrosine affected proactive inhibition both behaviorally and neurally. Specifically, increasing age was associated with a greater detrimental effect of tyrosine compared with placebo on proactive slowing. Moreover, with increasing age, tyrosine decreased fronto-striatal and parietal proactive signal, which correlated positively with tyrosine's effects on proactive slowing. Concluding, tyrosine negatively affected proactive response slowing and associated fronto-striatal activation in an age-dependent manner, highlighting the importance of catecholamines, perhaps particularly dopamine, for proactive response inhibition in older adults.
\end{abstract}

Key words: dopamine; functional MRI; healthy aging; response inhibition

\section{Significance Statement}

Healthy aging comes with altered dopamine functioning and is associated with reduced performance on cognitive control tasks, such as response inhibition. However, it is yet unclear whether reactive or proactive response inhibition is modulated by dopamine. We addressed this question by administering the catecholamine precursor tyrosine in a double blind, placebo-controlled, randomized intervention study. Tyrosine decreased proactive response slowing, not reactive stopping, as a function of increasing age. Concurrently, proactive fronto-striatal and parietal blood oxygen level-dependent (BOLD) signal decreased after tyrosine with increasing age. These findings, especially in striatum, demonstrate that proactive, rather than reactive response inhibition, is dopamine dependent. Moreover, tyrosine's effect on brain and cognition became detrimental with increasing age, questioning the cognitive enhancing potential of tyrosine in healthy aging. 


\section{Introduction}

The aging brain is characterized by alterations in dopamine functioning (Kaasinen and Rinne, 2002; Braskie et al., 2008). Age-related decreases in dopamine receptor and transporter binding have been linked to impairments in cognitive functions such as attention, episodic and working memory (Bäckman et al., 2006) and age-related increases in dopamine synthesis capacity have been related to decreased neural reward processing (Dreher et al., 2008). In aged experimental animals, administration of a D1 receptor agonist improved working memory performance (Cai and Arnsten, 1997). Similarly, enhancing dopamine levels in humans with the drug L-Dopa (the direct dopamine precursor) improved age-related impairments in episodic memory performance and reinforcement learning (Chowdhury et al., 2012, 2013).

Tyrosine is a large non-essential neutral amino acid (LNAA), naturally present in food. Tyrosine is the precursor of the catecholamines, converted to dopamine via L-Dopa and the enzymes tyrosine hydroxylase $(\mathrm{TH})$ and aromatic l-amino acid decarboxylase and to noradrenaline by dopamine $\beta$-hydroxylase (Molinoff and Axelrod, 1971). Research in rodents showed that orally administered tyrosine reaches the brain (Glaeser et al., 1983). Tyrosine administration increases dopamine metabolites in CSF, like homovanillic acid (HVA), in rats (Scally et al., 1977) and in patients with Parkinson's disease (Growdon et al., 1982). In young adults, tyrosine administration improved cognitive control functions such as response inhibition, task switching, and working memory, especially in demanding circumstances (for review, see Deijen, 2005; Jongkees et al., 2015). In the aging brain, tyrosine may similarly improve cognitive functioning.

Aging is accompanied by deficits in inhibitory functions, both in terms of the inhibition of irrelevant information, e.g., sensory suppression (Gazzaley et al., 2008; Healey et al., 2008), as well as in terms of response inhibition, such as in stop-signal tasks (Kramer et al., 1994; Bedard et al., 2002; van de Laar et al., 2011). Two forms of

Received January 29, 2017; accepted March 24, 2018; First published April 18, 2018.

The authors declare no competing financial interests.

Author contributions: M.B., B.B.Z., O.v.d.R., R.C., and E.A., designed research; M.B. and M.I.F. performed research; M.B., J.W., E.A., and M.I.F. analyzed data; B.B.Z. and O.v.d.R. contributed unpublished reagents/analytic tools; M.B., J.W., E.A., and R.C. wrote the paper.

This work was supported by the European Regional Development Fund and the Dutch provinces Gelderland and Overijssel Grant 2011-017004 (FOCOM). E.A. was supported by the Netherlands Organisation for Scientific Research (NWO) VENI Grant 016.135.023. R.C. was supported by the James McDonnell Foundation Grant 220020328 and by the NWO VICI Grant 453-14-015.

Acknowledgements: We thank Ilke van Loon and Ratigha Varatheeswaran for help with data collection and data processing.

\#Correspondence should be addressed to Mirjam Bloemendaal, Donders Institute for Brain, Cognition and Behaviour, Centre for Cognitive Neuroimaging, Radboud University, Kapittelweg 29, Nijmegen 6525EN, The Netherlands, E-mail: mirjambloemendaal@gmail.com.

DOI:http://dx.doi.org/10.1523/ENEURO.0035-17.2018

Copyright (C) 2018 Bloemendaal et al.

This is an open-access article distributed under the terms of the Creative Commons Attribution 4.0 International license, which permits unrestricted use, distribution and reproduction in any medium provided that the original work is properly attributed. response inhibition have been distinguished: reactive response inhibition is the process of canceling an ongoing response at the moment this is needed (i.e., outright stopping), whereas proactive response inhibition entails the preparation for stopping when this may become necessary, e.g., based on cues held in working memory. Age-related impairments have been shown in both reactive inhibition (measured with stop-signal reaction time; SSRT) and proactive inhibition (measured with anticipatory response slowing), particularly under high information load (i.e., high information processing demands for interpreting the stop-signal probability cues; Bloemendaal et al., 2016; Kleerekooper et al., 2016). It is unclear whether tyrosine-induced modulation of catecholaminergic signaling in older adults will affect reactive and/or proactive response inhibition. For reactive response inhibition, pharmacological animal and human genetic work shows both dopaminergic as well as noradrenergic involvement (Eagle et al., 2007; Congdon et al., 2009; Ghahremani et al., 2012; Rae et al., 2016; Schippers et al., 2016; see also Eagle and Baunez, 2010). Catecholaminergic modulation of proactive response inhibition has never been formally tested, but experimental animal work implicates dopamine in a variety of processes contributing to proactive response inhibition (Bari et al., 2009; Bari and Robbins, 2013). Further indirect evidence for a role of dopamine in proactive inhibition comes from neuroimaging studies. Specifically, midbrain signal was associated with stopsignal probability and RT adjustments (Boehler et al., 2011; Zandbelt et al., 2013).

In this neuro-imaging study, we investigated effects of acute, oral tyrosine administration on reactive and (loaddependent) proactive response inhibition and associated signal in dopamine-innervated fronto-striatal regions of the aging brain. We used a dose of $150 \mathrm{mg} / \mathrm{kg}$ body weight, in accordance with most previous studies in young volunteers (Shurtleff et al., 1994; Neri et al., 1995; Thomas et al., 1999; Magill et al., 2003; Mahoney et al., 2007), but see work by Colzato and colleagues for beneficial effects on cognition in young volunteers with much smaller doses (Colzato et al., 2013, 2014a, 2014b; Steenbergen et al., 2015). By investigating older adults, we could also assess the potentially beneficial effects of tyrosine in aging. We expected to find beneficial effects of tyrosine on brain and behavior across the group of older adults. Given our recent findings of age-related differences in the peripheral plasma response to oral tyrosine administration (van de Rest et al., 2017) and given differences in the effect of dopaminergic agents between younger and older adults (Turner et al., 2003), we also explored the possibility that tyrosine's effects would vary as a function of age. Using a smaller age range, we do not expect generational differences to influence the effects of dopaminergic agents, such as differences in education or computer experience that would differ in a cross-sectional design with larger age differences. The oldest relative to the youngest older adults are presumably most dopamine deprived and, thus, may benefit most from administration of dopamine's precursor tyrosine. However, whereas aging has been associated with reduced dopamine receptor and transporter binding, 

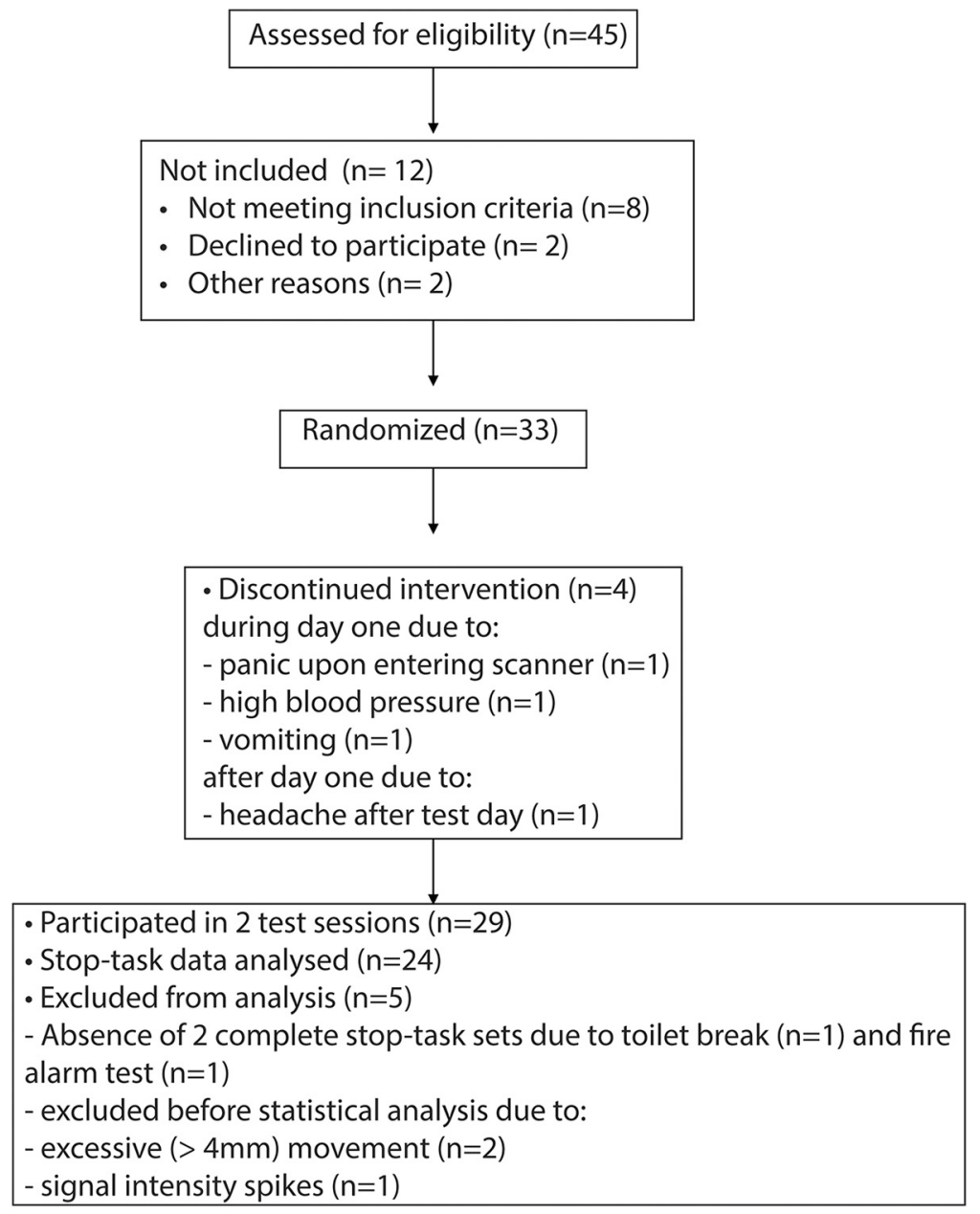

Figure 1. Flowchart of participants through the study.

it has also been shown to be accompanied by upregulation of (dorsal) striatal dopamine synthesis capacity (Braskie et al., 2008; Berry et al., 2016). This upregulation of synthesis capacity has been related to, if anything, worse rather than better neurocognitive functioning relative to young adults (Dreher et al., 2008; Berry et al., 2016). Moreover, a recent study with multiple oral tyrosine doses $(100,150$, and $200 \mathrm{mg} / \mathrm{kg}$, but no placebo condition) showed decreased cognitive performance with increased tyrosine dose in older adults (van de Rest et al., 2017). Therefore, in the current placebo-controlled study, administration of a high dose $(150 \mathrm{mg} / \mathrm{kg})$ of the dopamine precursor tyrosine might also impair instead of improve neuro-cognitive function in the oldest adults, with presumably the greatest upregulated dopamine synthesis capacity.

\section{Materials and Methods}

\section{Participants}

Participants met the following criteria: aged between 60 and 75 , right handed, functioning within normal limits of general cognitive function [mini-mental state examination (MMSE); Folstein et al., 1975; cutoff $\geq 27$ of 30 ), no depression or anxiety [hospital anxiety and depression scale (HADS) score <11; Bjelland et al., 2002], an estimated verbal IQ > 85 (Schmand et al., 1991), not suffering from neurologic or psychiatric disorders, no first degree relatives suffering from schizophrenia, bipolar disorder, or major depressive disorder, no history of alcohol or drug abuse, no habitual smoking defined as less than a pack of cigarettes a week for the last year, current or past (within last 12 months) participation in a specific cognitive training program, no contraindications for MRI, no daily use of $\beta$ blockers, no use of medication interfering with tyrosine's action (monoamine oxidase inhibitors and other antidepressants, sympathomimetic amines, and opioids), no thyroid problems and no low-protein diet, no endocrine or metabolic disorders such as hepatic or renal problems, no repetitive strain injury (RSI) or sensorimotor handicaps, blindness, or colorblindness.

Participants were recruited via adverts in local newspapers, websites, and associations for older adults. After informing potential participants about the inclusion criteria, 45 older adults were invited for a pre-screen session. After the pre-screen, we invited 33 participants for the test sessions (Fig. 1). Of these 33, 29 participants completed two test sessions. Of the four participants who did not complete all test sessions, three participants were excluded during test day 1 (due to panic on entering the scanner, high blood pressure, or vomiting) and one after 
test day 1 (due to headache after the test day). Of the 29 participants who completed both test days, a final sample of 24 healthy older adults were included in the analyses (mean age: 67.5, range 61-72, 15 men). Of the five participants who were not included in the analyses, two participants did not finish the stop-task on one of the sessions, and three participants were excluded before statistical data analysis: two due to excessive movement (>4-mm translation) and one due to signal intensity spikes.

The experiment was approved by the local ethics committee (CMO 2014-1172), and all participants gave written informed consent. The study was preregistered at the Dutch trial register (www.trialregister.nl) 159 under number NTR4938.

\section{Intervention}

Our participants received a dosage of $150 \mathrm{mg} / \mathrm{kg}$ tyrosine or placebo, adjusted to body weight as determined during the pre-screen session (Procedure). The European Food Safety Authority determined in July 2011 that tyrosine is proven to contribute to the normal synthesis of catecholamines (EFSA Panel on Dietetic Products Nutrition and Allergies, 2011). In accordance with most previous studies in young volunteers (Shurtleff et al., 1994; Neri et al., 1995; Thomas et al., 1999; Magill et al., 2003; Mahoney et al., 2007; but see Colzato et al., 2013, 2014a, 2014b; Steenbergen et al., 2015), we used a dosage of $150-\mathrm{mg}$ tyrosine or placebo per kilogram of body weight. For reference, a daily required intake of phenylalanine and tyrosine for adults was estimated at $14 \mathrm{mg} / \mathrm{kg} / \mathrm{d}$ (World Health Organization, 1985) or $39 \mathrm{mg} / \mathrm{kg} / \mathrm{d}$ in a more recent study (Basile-Filho et al., 1998).

The placebo product was a mixture of $54 \mathrm{mg} / \mathrm{kg}$ dextrine-maltose (i.e., carbohydrates; product name Fantomalt by Nutricia) with maizena $(110 \mathrm{mg} / \mathrm{kg}$, ratio Fantomalt/cornstarch $=\sim 1 / 2$ ). The ratio of Fantomalt to cornstarch was adjusted such that the placebo and tyrosine mixture have an equal energy value, similar structure and aftertaste. Equal taste experience for tyrosine and placebo was ensured in a formal sensory experiment by a specialized dietician from the Division of Human Nutrition of Wageningen University (E.Siebelink).

The tyrosine and placebo product were mixed with a carrier: banana-flavored yoghurt (Arla Food Nederland). Weighing of the doses and preparing and coding the samples was performed by a staff member who was not further involved in the study.

\section{Physiologic and mood measurements}

To monitor wellbeing, participants completed mood ratings, assessing calmness, contentness, and alertness (Bond and Lader, 1974). Moreover, we assessed levels of the catecholamine metabolites [HVA, vanillylmandelic acid (VMA), 3-methoxy-4-hydroxyphenylglycol (MOPEG), and 3,4-dihydroxyphenylacetic acid (DOPAC) in urine to measure peripheral effects.

\section{Procedure}

All participants were tested between November 2014 and August 2015 at the Donders Center for Cognitive
Table 1. Trait demographics and neuropsychological tests

Variable

Age (years)

Sex (women/men)

Verbal IQ

HADS total

HADS anxiety

HADS depression

MMSE

BIS-11 motor

BIS-11 cognitive

BIS-11 non-planning

BIS-11 total

$67.5(0.6)$

W: $9 ; \mathrm{M}: 15$

$114.5(2.0)$

$3.5(0.5)$

$2.3(0.4)$

$1.2(0.3)$

$29.1(0.3)$

$20.9(0.6)$

$14.8(0.6)$

$21.7(0.7)$

$57.4(1.1)$

Data represent mean (SEM) except for the variable sex, for which data reflect frequencies. Verbal IQ is defined by scores on the Dutch version of the NART, MMSE, BIS-11, subscales and total score. Men and women are equally distributed across the whole group.

Neuroimaging, Nijmegen, The Netherlands. Participants were pre-screened in a separate 4-h session and trained on the tasks. During this pre-screen session, participants signed informed consent, were screened on all the in- and exclusion criteria, and completed several neuropsychological measures: verbal IQ as measured with the Dutch version of the NART (NLV; Schmand et al., 1991), HADS (Bjelland et al., 2002), and the Barratt impulsiveness scale (BIS-11; Patton et al., 1995; Table 1). Moreover, participants were trained on the three tasks they were going to perform during the test sessions and were weighed to determine the individual tyrosine dose.

On both test sessions (of at least one week apart), the same procedure was followed except for the supplement taken: tyrosine or placebo, counterbalanced across participants.

An independent researcher randomized the order of tyrosine administration (tyrosine or placebo on the first test session) by means of a computer-generated order. The day before the test session from 10PM onwards, participants were asked to refrain from eating and drinking anything but water until arriving at the center the next morning, and to refrain from taking any medication that they would not take during both testing sessions, to avoid an unbalanced influence of this medication. The overnight fast prevents large variability in plasma LNAA levels between participants caused by the previous meal (Fernstrom et al., 1979). A similar fasting procedure has been adopted in other research using tyrosine supplementation (Lieberman and Wurtman, 1985; Banderet and Lieberman, 1989; Shurtleff et al., 1994; Mahoney et al., 2007; Colzato et al., 2013). Testing started from 8 or 10 A.M. at the latest and took $\sim 4.5 \mathrm{~h}$ (Fig. 2). The time of testing was kept similar for the placebo and tyrosine session of each participant (i.e., maximal difference between test sessions was $1 \mathrm{~h}$, except for one participant for who the difference was $1.5 \mathrm{~h}$ ).

The test day started with assessing subjective feelings of wellbeing measured with Bond \& Lader visual-analog ratings. Blood pressure and heart rate were assessed, and a urine sample was provided. Next, participants started re-familiarization with all three tasks (always in the same order). The yoghurt mixture (with tyrosine or pla- 


\begin{tabular}{|c|c|c|c|c|c|}
\hline $\begin{array}{l}\text { - Wellbeing rating } \\
\text { - Blood pressure \& } \\
\text { heart rate } \\
\text { - Urine sample } \\
\text { (labeled T0) }\end{array}$ & $\begin{array}{l}\text { - Ingestion of } \\
\text { tyrosine or } \\
\text { placebo }\end{array}$ & $\begin{array}{l}\text { - Practicing tasks } \\
\text { - Wellbeing ratings } \\
\text { - Blood pressure \& } \\
\text { heart rate } \\
\text { (labeled T1) }\end{array}$ & $\begin{array}{l}\text { - MRI scans includ- } \\
\text { ing stop-signal task }\end{array}$ & $\begin{array}{l}\text { Post-scanning part } \\
\text { including: } \\
\text { - Wellbeing ratings } \\
\text { - Blood pressure \& } \\
\text { heart rate } \\
\text { - Urine sample } \\
\text { - Neuropsycholog- } \\
\text { ical testing } \\
\text { (labeled T2) }\end{array}$ & End of session \\
\hline T-30 & T0 & T15 & T90 & T185 & T250 \\
\hline
\end{tabular}

Figure 2. Schematic of the two test sessions: placebo and tyrosine.

cebo) was provided such that participants entered the scanner 90 min after ingestion. Maximal concentration of plasma elevation and cognitive effects are seen approximately after $1.5 \mathrm{~h}$ and are normalized after $6-8 \mathrm{~h}$ (Glaeser et al., 1979). The stop-signal task (described below) was the first task performed in the scanner, followed by a working memory task. Scanning took $\sim 100 \mathrm{~min}$. On exiting the scanner, a second urine sample was provided. After scanning, participants performed the third task measured effort discounting and completed a neuropsychological test battery assessing: immediate and delayed story recall (Wilson et al., 1985), digit span forward and backward (Wechsler, 1997), Stroop cards (Stroop, 1935), and verbal fluency (Tombaugh et al., 1999). Participants' blood pressure, heart rate, and wellbeing were monitored three times during the test session.

\section{Experimental design: load-dependent stop-signal anticipation task}

Participants performed a stop-signal anticipation task consisting of three levels differing in information load, which were presented in alternating blocks (Bloemendaal et al., 2016; Fig. 3). The paradigm consisted of Go trials and Stop trials. On every trial, a bar moved at a constant speed from a lower horizontal line toward an upper horizontal line, reaching a middle line (flanked by two vertical lines) in $800 \mathrm{~ms}$. The Go task was to bring the bar to a halt as close to the middle line as possible, by pressing a button with the right index finger. A minority of trials were Stop trials. On Stop trials, the bar stopped moving automatically before reaching the middle line (the stop signal). This stop signal instructed the participants to withhold the planned Go response. The middle horizontal line and the two vertical lines represented cues that indicated stopsignal probability context by varying in color. To manipulate information load, the task consisted of three levels that were alternated in short blocks (Last alinea of Experimental design section). Between levels, stop-signal probability cues were varied in amount as well as in complexity. The stop-signal probability could be anticipated on the basis of the color of the cues (i.e., horizontal and vertical lines, presented $500 \mathrm{~ms}$ before the onset of the moving bar). Level A was the level with the least information load, with only white cues (stop probability of $26 \%$ ) and green cues (stop probability of $0 \%$ ). In level B, there were five types of Go trials with varying stop-signal probability, using an intuitive color range for the cues (Zandbelt and Vink, 2010): green, 0\%; yellow, 17\%; amber, $22 \%$; orange, $28 \%$; and red, $35 \%$, with a mean of $26 \%$ stop probability. The non-green trials are collectively called $>0 \%$ trials. Level $\mathrm{C}$ consisted of the same types and numbers of stop-signal probability cues as level B. However, in level $\mathrm{C}$ only one of the vertical lines signaled the correct stop-signal probability context. The correct
Level A

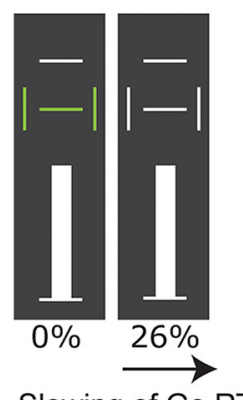

Slowing of Go RT
Level B

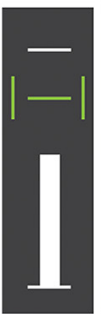

$0 \%$

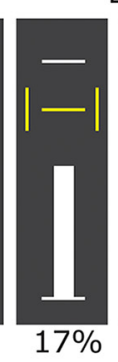

$17 \%$

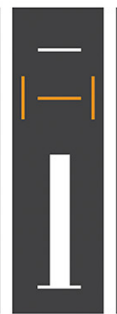

Slowing of Go RT

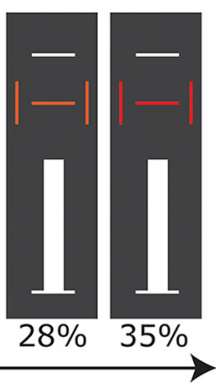

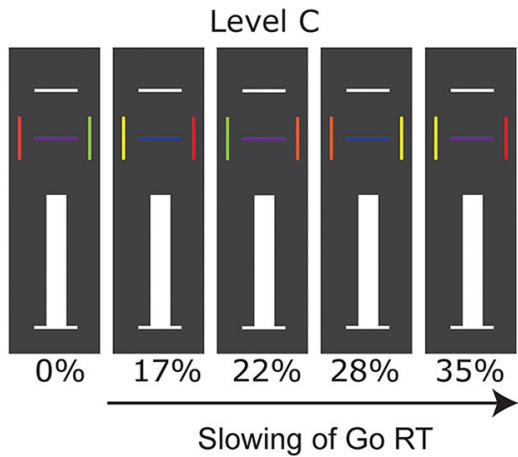

Figure 3. Load-dependent stop-signal anticipation task. Information load increased with level. Percentages reflect the probability a trial will be a Stop trial rather than a Go trial. For level B and C, stop-signal probability increased as a function of cue color. Every level contained 70 trials with $0 \%$ (green) and 270 trials with $>0 \%$ (white in level A and various colors in levels B and C) stop-signal probability. Of these $270>0 \%$ trials, 70 were Stop trials, with a mean stop-signal probability of $26 \%$. For levels B and C, each $>0 \%$ trial type contained 50 Go trials, plus a varying amount of Stop trials per color resulting in varying stop-signal probabilities (in between brackets): 10 yellow (17\%), 14 amber (22\%), 19 orange (28\%), and 27 red (35\%). 
side could be identified by the color of the middle line: a blue middle line indicated that the left vertical line color was valid, whereas a purple middle line indicated that the right vertical line color was valid.

We instructed participants that going and stopping were equally important and that it would not always be possible to suppress a response when a stop signal occurred. Participants were not informed of the exact stop-signal probabilities but were told that stop signals in all levels would not occur on trials with a green cue, and that stop signals in levels B and C were least likely in the context of a yellow cue and most likely in the context of a red cue, with the amber and orange cues coding intermediate, and, respectively, decreasing, stop-signal probabilities.

To ensure roughly equal numbers of successful and unsuccessful Stop trials, a staircase procedure adjusted stop-signal delay by $25 \mathrm{~ms}$ depending on stopping performance. Levels were presented in 34 blocks, each lasting $27 \mathrm{~s}$ and consisting of 10 trials, with an intertrial interval of $1000 \mathrm{~ms}$. The sequence of trials and blocks were pseudo randomized (ensuring that the first three blocks of the task were always in order of levels A-B-C). Every level contained 70 trials with $0 \%$ (green) and 270 trials with $>0 \%$ (white in level $A$ and various colors in levels B and C) stop-signal probability. Of these $270>0 \%$ trials, 70 were Stop trials, with a mean stop-signal probability of $26 \%$. For levels B and C, each $>0 \%$ trial type contained 50 Go trials, plus a varying amount of Stop trials per color resulting in varying stop-signal probabilities (in between brackets): 10 yellow (17\%), 14 amber $(22 \%), 19$ orange $(28 \%)$, and 27 red $(35 \%)$. Two rest blocks of $20 \mathrm{~s}$ each were implemented at one-third and two-thirds of the task, respectively. The total task duration was $\sim 45 \mathrm{~min}$. During the pre-screening, each level was explained and practiced separately for 48 trials (level A) and 72 trials (levels B and C). Participants were asked to repeat task instructions to ensure sufficient understanding. Then they practiced the task (levels were presented in alternating blocks) for $10 \mathrm{~min}$. On each test day, instructions were rehearsed and the 10-min practice was repeated.

\section{Behavioral data analysis \\ Stop-signal task}

All data were in accordance with the main assumptions of the race model (Logan and Cowan, 1984). Reactive response inhibition was measured by calculating the SSRT (stopping latency), according to the integration method (Verbruggen and Logan, 2009). Outliers on any outcome measure were determined using Grubbs' test (i.e., they do not differ $>2.8 *$ SD from the mean; Grubbs, 1969). An ANOVA of SSRTs was used with the within-subjects factors level (A, B, C) and intervention (tyrosine, placebo).

RT slowing as a function of increasing stop-signal probability, indicated by the colored cues, indexed proactive response inhibition. Task non-compliance was determined by a negative difference on median RTs between $0 \%$ (green) and $>0 \%$ (white) trials during the lowest cognitive load (level A). No participants were excluded based on this criterion. For each level, the slope of RTs was calculated as a function of stop-signal probability using a general linear model, resulting in a $\beta$ value for the slowing slope. Hence, for level A, the slowing slope was calculated using the two proactive trial types [0\% (green cues) and $26 \%$ (white)]. For levels B and C, the five proactive trial types were included in the slowing slope [0\% (green cues), 17\% (yellow), 22\% (orange), 28\% (amber) and 35\% (red)]. Task instructions implied differential processing of $0 \%$ and $>0 \%$ stop-signal probability trials, resulting in more slowing on $>0 \%$ than $0 \%$ trials (i.e., a positive difference between these trial types). Level A consists of fewer cells than levels $B$ and $C$ and was therefore not compared with the other levels for the proactive inhibition analyses. An ANOVA was performed using the withinsubjects factors level (levels B and C) and intervention (tyrosine, placebo). On lack of an interaction effect between level and intervention, the effect of intervention on slowing slope was assessed and reported on the average slowing slope irrespective of level. For effects of level independent of tyrosine manipulation, see Bloemendaal et al. (2016).

To assess the relation between age and tyrosine's effects on reactive and proactive response inhibition, we added the covariate age in an ANOVA using factors intervention and level for proactive RT slowing and SSRT. On significant effects or interactions with intervention, we tested for a possible interaction between administration order and intervention. On lack of interaction effects with level, the effect of intervention and age was assessed irrespective of level.

\section{Neuropsychological measures and additional measures: catecholamine metabolites in urine, physiologic measures, and wellbeing}

Outliers on any outcome measure were determined using Grubbs' test (Grubbs, 1969), resulting in exclusion of one outlier on the HVA and one on DOPAC urine levels. Performance on neuropsychological tasks (digit span, verbal fluency, story recall, Stroop, box completion, letter cancellation) was assessed using paired t-tests comparing scores on the tyrosine session with the placebo session. The effect of tyrosine administration on catecholamine metabolites HVA, VMA, MOPEG, and DOPAC in urine was determined using four ANOVAs with within-subject factors time (T0, T2) and intervention (tyrosine, placebo). The effect of time on blood pressure, heart rate, and subjective wellbeing was assessed using ANOVAs with factor time (T20, T90, T240). The effect of tyrosine administration on these measures during the baseline corrected therapeutic window $(\mathrm{T} 1-\mathrm{T} 0)$ was assessed with a paired $t$ test. Possible modulation of tyrosine's effect on catecholamine metabolites, physiologic and neuropsychological measures by age was determined by adding the covariate age in an ANOVA on these measures using factors intervention (tyrosine, placebo). On significant effects, the influence of administration order was assessed in a separate ANOVA using within-subjects factor intervention (tyrosine, placebo), between-subjects factor administration order (tyrosine on first or second test day) and covariate age. 


\section{MRI data acquisition and pre-processing}

Whole-brain imaging was conducted on a Siemens TIM Trio 3T scanner (Magnetrom Skyra Tim, Siemens Medical Systems), using a 32-channel head coil. Functional data were obtained using a multi-echo gradient T2*-weighted echo-planar scanning sequence (Poser et al., 2006) with blood oxygen level-dependent (BOLD) contrast (34 axialoblique slices, repetition time, $2070 \mathrm{~ms}$; echo-times, 9.0, $19.3,30.0$, and $40.0 \mathrm{~ms}$; in plane resolution, $3.5 \times 3.5 \mathrm{~mm}$; slice thickness, $3 \mathrm{~mm}$; distance factor, 0.17 ; field of view, $224 \mathrm{~mm}$; flip angle, $\left.90^{\circ}\right)$. Visual stimuli were projected on a screen and were viewed through a mirror attached to the head coil. In addition, a high-resolution T1-weighted magnetization-prepared rapid-acquisition gradient echo anatomic scan was obtained from each participant (192 sagittal slices; repetition time, $2.3 \mathrm{~s}$; echo time, $3.03 \mathrm{~ms}$; voxel size $1.0 \times 1.0 \times 1.0 \mathrm{~mm}$; field of view $256 \mathrm{~mm}$ ).

Preprocessing and mass-univariate data analysis were performed using SPM8 software (Statistical Parametric Mapping; Wellcome Trust Center for Cognitive Neuroimaging). Realignment parameters were estimated for the images acquired at the first echo-time and subsequently applied to images resulting from the three other echoes. The echo images were combined by weighting with a parallel-acquired inhomogeneity-desensitized algorithm, assessing the signal-to-noise ratio as described by Poser et al. (2006). Thirty volumes, acquired before the task, were used as input for this algorithm. After data quality check (i.e., for signal intensity spikes), the echo combined and realigned images were slice time corrected to the middle slice. The functional images were coregistered to the T1 scan. A sample-specific template was created by segmenting each individual T1 and using diffeomorphic anatomic registration to place each participant's gray and white matter images in a study-specific space (Ashburner, 2007). Deformation parameters were stored in a subjectspecific flow field. The coregistered fMRI images and anatomic T1 scan were nonlinearly normalized to the sample-specific anatomic template (using the subjectspecific flow field), affine-aligned into a Montreal Neurologic Institute template, and finally smoothed using an 8.0-mm full width at half maximum Gaussian filter.

To exclude activation outside gray matter from second level analyses, GM normalized maps from all subjects in the sample were used to create an average gray matter mask, which was thresholded at a value of 0.4 (voxels with computed GM fractions $>40 \%$ were selected, set after visual inspection) and applied as an explicit mask during second-level analysis.

\section{fMRI task analysis}

The general linear model was set up as in (Bloemendaal et al., 2016), including twelve regressors of interest. For each level, we included four regressors: one modeling all Go trials (i.e., containing $0 \%$ and $>0 \%$ stop-signal probability trials) and a corresponding parametric (i.e., proactive) regressor modeling stop-signal probability (six regressors: Go level A, Proactive level A, Go level B, Proactive level B, Go level C, Proactive level C). In level A, the parametric regressor consisted of two trial types. In level $B$ and $C$, the parametric regressors consisted of five trial types. An actual stop-signal appeared on a proportion of $>0 \%$ trials. These Stop trials were separately modeled as StopSuccess trials and StopFailure trials, based on whether or not the behavioral response was inhibited (six regressors: StopSuccess level A, StopFailure level A, StopSuccess level B, StopFailure level B, StopSuccess level C, StopFailure level C). As regressors of non-interest, we included a regressor for missed trials across all levels (i.e., no button box response on a Go trial), as well as a regressor modeling task instructions at the beginning of each miniblock. Moreover, twenty four realignment parameters were modeled as regressors of non-interest (six rigidbody movement parameters, plus Volterra expansion of these: first derivatives and quadratic derivatives of the original as well as first derivatives; Lund et al., 2005). Finally, to prevent contribution of global signal changes, we included signal from segmented out-of-brain voxels in the model as regressor of non-interest. All regressors of interest were modeled as delta functions at the onset of the trial and were convolved with a canonical hemodynamic response function. Time series were high-pass filtered (128-s cutoff) and serial correlations were corrected using an autoregressive (AR)1 model during classical (ReML) parameter estimation. Parameter estimates for the regressors of interest, derived from the mean least-squares fit of the model to the data, were used to estimate contrasts on the first level.

At the subject-specific, first level, we specified reactive and proactive contrasts within, across, and between levels. The first level contrast images were subsequently used in a second level random effects analysis to assess consistent effects across participants as well as the effects of intervention. Reactive response inhibition can be assessed using two different contrasts: StopSuccess > StopFailure or StopSuccess $>$ Go. The contrast StopSuccess $>$ StopFailure provides better control for stimulus-driven processing (i.e., presentation of the stop signal), and is orthogonal by design to the proactive inhibition contrast (which also involves the Go trials). The contrast StopSuccess $>$ Go provides better control for the timing of the Go responses (i.e., Go and StopSuccess RTs are both slower than Stop Failure) and the outcome of the trial (i.e., both successful in Go and StopSuccess). We report effects on both types of contrasts. The parametric proactive regressors constituted the contrast for proactive response inhibition.

We assessed the main task effects of proactive and reactive response inhibition using the contrasts across levels and intervention. We explored level $*$ intervention interactions within reactive and proactive response inhibition. On non-significant interactions, we assessed the effects of intervention across levels, comparing tyrosine and placebo sessions using a paired $t$ test. On wholebrain corrected significant results, we assessed brainbehavior correlations in these clusters by extracting $\beta$ weights using Marsbar (Tzourio-Mazoyer et al., 2002).

The sample-specific gray matter mask was applied as an explicit mask to the second-level statistics (see above). Statistical inference $(\mathrm{pFWE}<0.05)$ was performed at the cluster level, correcting for multiple comparisons over the 
A

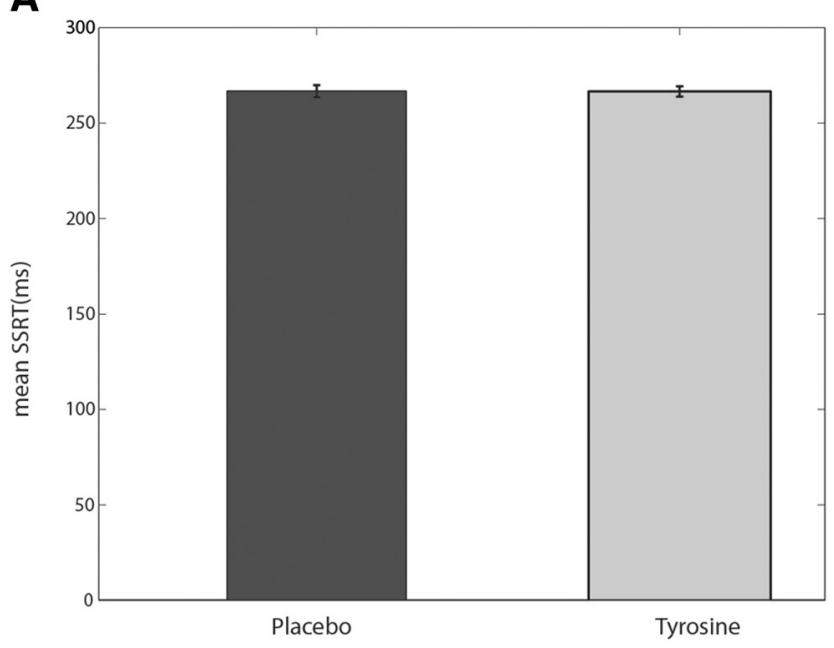

C

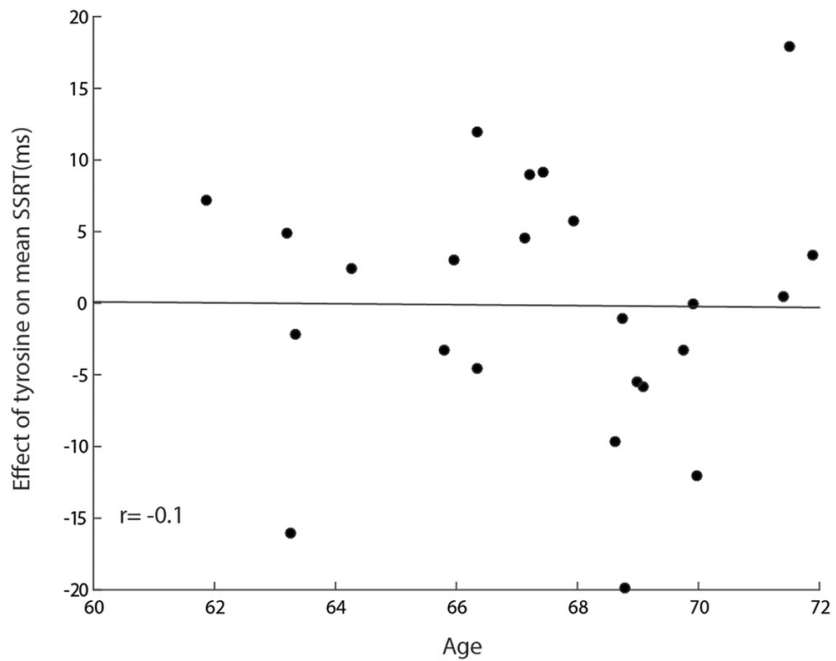

B

Proactive response inhibition

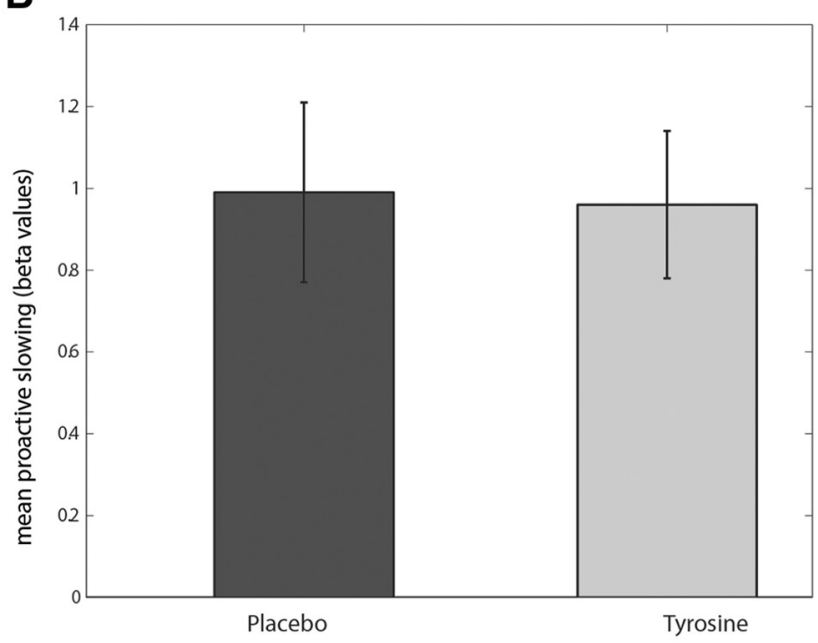

D

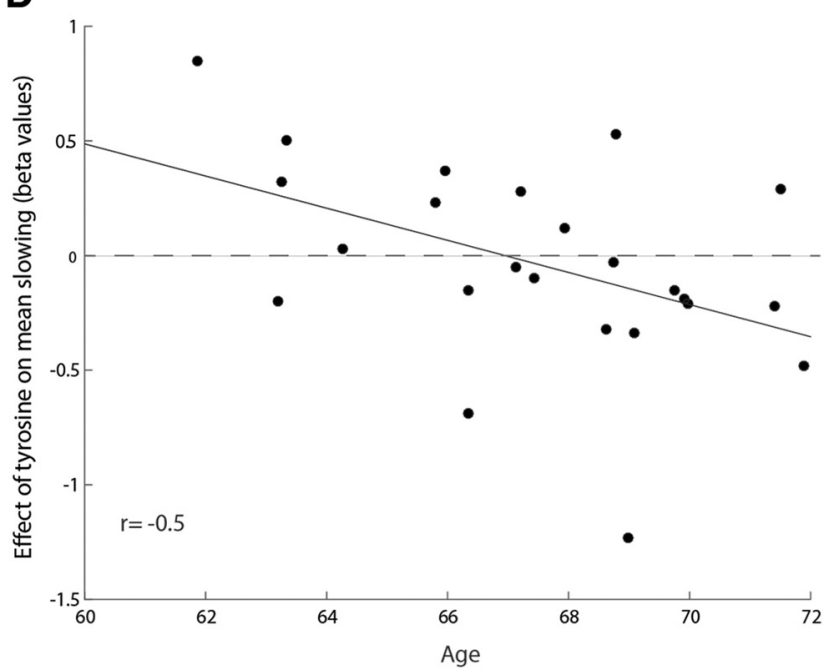

Figure 4. A, SSRT on placebo and tyrosine session across levels. $\boldsymbol{B}$, Proactive $\beta$ slowing slopes on placebo and tyrosine session. Data represents mean, error bars represent SEM. $\boldsymbol{C}$, The effect of tyrosine compared with placebo on SSRT was not modulated by age $(r=-0.1, p=0.96)$. $\boldsymbol{D}$, With increasing age, tyrosine relative to placebo attenuated proactive RT slowing $(r=-0.45, p=0.03)$, i.e., the degree to which participants slowed their responses with increasing stop-signal probability $\mathrm{a}_{\mathrm{a}}$.

whole brain. The intensity threshold necessary to determine the cluster-level threshold was set at $p<0.001$, uncorrected. On significant cluster-level activation, we assessed simple effects using subsequent ANOVAs or paired $t$ tests.

\section{Results}

\section{Behavioral results}

Trait demographics and trait neuropsychological test scores are presented in Table 1. For a summary of statistical tests see Table 11.

\section{Reactive response inhibition}

Race model assumptions. Data were in compliance with the main assumptions of the race model (Logan and Cowan, 1984). For each level and age group separately, mean response times (RTs) were faster on StopFailure versus $>0 \%$ trials (paired $t$ test, all $p<0.05$ ) and mean RTs were faster for StopFailure RTs for short versus long SSDs (paired $t$ test, all $p<0.05)$. Inhibition functions represent the probability of successfully inhibiting a response for every SSD, where the probability to inhibit decreases as the stop-signal is presented more closely to the moment that the response is made (Logan and Cowan, 1984). For each level, individual inhibition functions were calculated and displayed decreasing inhibition probability as a function of SSD.

On non-significant tyrosine effects on SSRT between levels $\left(F_{(2,46)}=1.19, p=0.31\right)_{\mathrm{a} 1}$, we performed our analyses across levels. Tyrosine administration did not affect SSRT across levels $\left(F_{(1,23)}<1\right)_{\mathrm{a} 2}$ and when assessing whether the effect of tyrosine administration depended on age, no effect was observed either $\left(F_{(1,22)}<1\right)_{\mathrm{b} 1}$ (Fig. $4 A, C)$. Across intervention sessions, increasing age was associated with a slower SSRT (main effect of age: $F_{(1,22)}$ $\left.=4.3, p=0.05, \eta_{p}^{2}=0.16\right)_{\mathrm{b} 2}$.

\section{Proactive response inhibition}

On non-significant tyrosine effects on RT slowing between levels $\left(F_{(2,46)}<1\right)_{c}$, we performed our analyses 


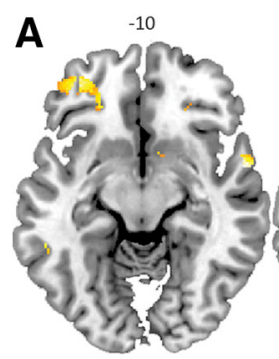

B

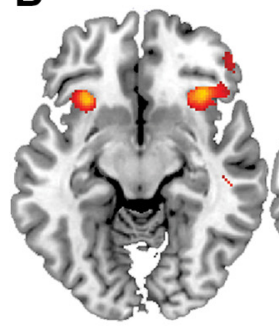

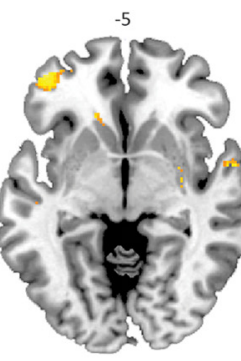

$-5$

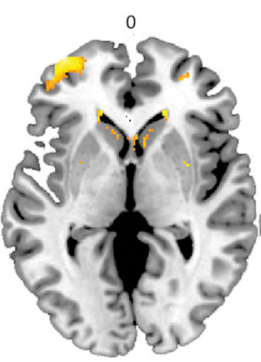

0
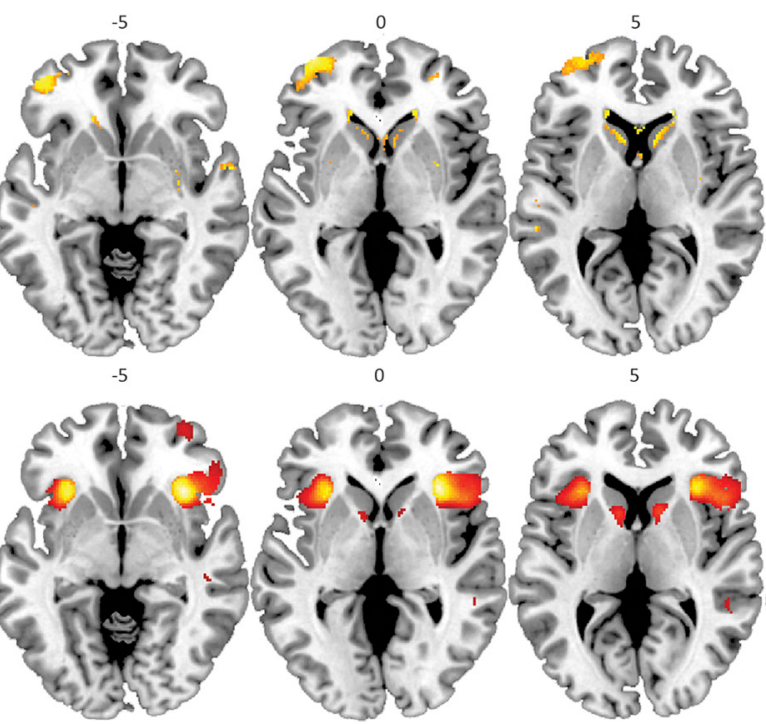

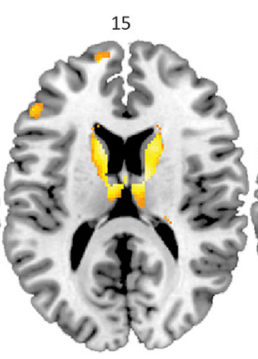

15

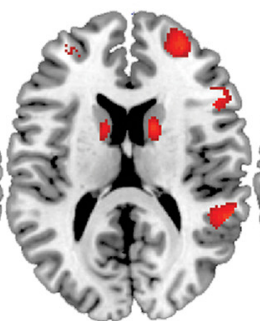

40

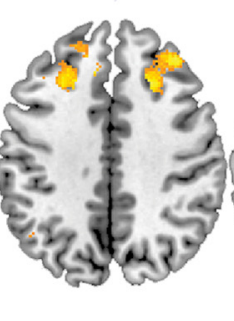

40

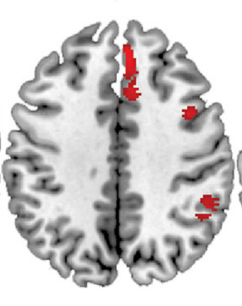

55

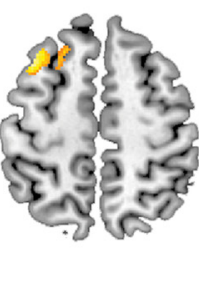

55

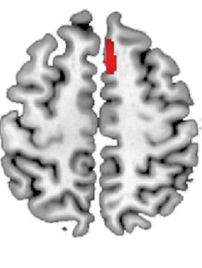

Figure 5. $\boldsymbol{A}$, Main task effects across test sessions and level for reactive response inhibition - StopSuccess $>$ fail. Images are thresholded at $p<0.001$ uncorrected (for illustration purposes), cluster-level (pFWE $<0.05$ ) significant clusters are listed in Table 2 . $\boldsymbol{B}$, Main task effects across test sessions and level for reactive response inhibition - StopSuccess $>$ Go. Images are thresholded at $p<0.001$ uncorrected (for illustration purposes), cluster-level (pFWE $<0.05$ ) significant clusters are listed in Table $3_{h}$.

across levels. Across levels and participants, tyrosine administration did not affect slowing $\beta$ values (reflecting increasing slowing with increasing stop chance; $F_{(1,23)}<$ $1)_{d}$. However, when adding age as a covariate, intervention did modulate proactive RT slowing (intervention * covariate age interaction: $F_{(1,22)}=5.7, p=0.03, r=$ $-0.5_{\mathrm{e} 1}$; main intervention: $F_{(1,22)}=5.6, p=0.03, \eta_{p}^{2}=$ $0.20)_{e 2}$ (Fig. 4B). Specifically, increasing age was related to a greater detrimental effect of tyrosine administration on RT slowing. Administration order did not interact with tyrosine administration on proactive slowing $\left(F_{(1,21)}=2.4\right.$, $p=0.14)_{\mathrm{f}}$ (Fig. 4D).

In sum, the effect of tyrosine administration on behavioral measures of reactive response inhibition (i.e., SSRT) was not significant. However, age negatively modulated the effect of tyrosine on proactive response slowing: increasing age was associated with a greater detrimental effect of tyrosine on proactive slowing compared with placebo.

\section{fMRI results}

Reactive and proactive inhibition activate frontoparietal networks and basal ganglia

At our whole-brain corrected threshold of pFWE $<0.05$ (cluster-level), main task effects revealed responses in a frontoparietal and striatal task network for reactive and proactive response inhibition (Figs. 5, 6; Tables 2-4) g,h,i and deactivation of, e.g., motor cortex in the reactive response inhibition network, as shown previously for the current task in young and older adults (Bloemendaal et al., 2016) and for similar paradigms (Zandbelt and Vink, 2010; Kleerekooper et al., 2016).

\section{Tyrosine's effects on reactive response inhibition}

(StopSuccess $>$ StopFailure and StopSuccess $>$ Go)

In accordance with the behavioral results, no level * intervention interactions were observed during reactive response inhibition. Hence, effects of intervention are reported across level. Tyrosine did not affect neural signal during both contrasts of reactive inhibition (StopSuccess $>$ StopFailure and StopSuccess $>$ Go $)_{j, k}$. A positive correlation between age and the effect of tyrosine on reactive response inhibition (StopSuccess $>$ StopFailure) was observed in the right angular gyrus (Fig. 7; Table 5). With increasing age, tyrosine increased angular gyrus responses compared with placebo. None of these clusters demonstrated a brain-behavior correlation between tyrosine's effect on reactive inhibition $\beta$ values and SSRT.
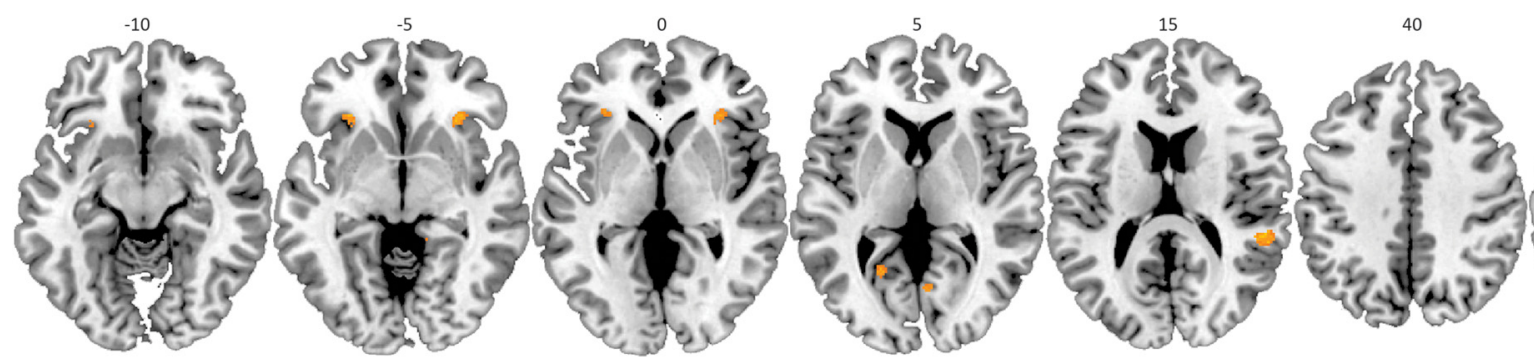

55

Figure 6. Main task effects across test sessions and level for proactive response inhibition (parametric regressors of Go). Images thresholded at $p<0.001$ uncorrected (for illustration purposes), cluster-level (pFWE $<0.05$ ) significant clusters are listed in Table $4_{i}$. 
Table 2. Whole-brain cluster-level significant task regions during reactive response inhibition across levels (StopSucces $>$ StopFailure)

\begin{tabular}{|c|c|c|c|}
\hline Region & $\begin{array}{l}\text { Peak MNI } \\
\text { coordinates }\end{array}$ & $\begin{array}{l}\text { pFWE } \\
\text { value }\end{array}$ & $\begin{array}{l}\text { Number of } \\
\text { voxels in } \\
\text { cluster }\end{array}$ \\
\hline Right caudate & 18324 & $<0.001$ & 1981 \\
\hline Left caudate & -101510 & & \\
\hline $\begin{array}{l}\text { Left middle orbito-frontal } \\
\text { gyrus }\end{array}$ & -38622 & $<0.001$ & 1258 \\
\hline Left middle frontal gyrus & -381755 & $<0.001$ & 1567 \\
\hline $\begin{array}{l}\text { Left medial superior frontal } \\
\text { gyrus }\end{array}$ & -183046 & & \\
\hline Right middle frontal gyrus & 222440 & $<0.001$ & 894 \\
\hline
\end{tabular}

The reactive response inhibition contrast StopSuccess > Go did not yield a correlation with $\mathrm{age}_{\mathrm{m}}$.

Tyrosine's effects on proactive response inhibition (parametric regressor of Go)

In accordance with the behavioral results, no level * intervention interactions were observed during proactive response inhibition. Hence, effects of intervention are reported across level.

Table 3. Whole-brain cluster-level significant task regions during reactive response inhibition across levels (StopSuccess $>$ Go) ${ }_{\mathrm{h}}$

\begin{tabular}{lllc}
\hline Region & $\begin{array}{l}\text { Peak MNI } \\
\text { coordinates }\end{array}$ & \multicolumn{1}{c}{$\begin{array}{l}\text { pFWE } \\
\text { value } \\
\text { Right insula }\end{array}$} & $\begin{array}{r}\text { No. voxels } \\
\text { in cluster }\end{array}$ \\
$\begin{array}{l}\text { Right inferior frontal } \\
\text { operculum }\end{array}$ & 51187 & $<0.001$ & 4104 \\
$\begin{array}{l}\text { Left insula } \\
\text { Right caudate }\end{array}$ & $-3021-5$ & $<0.001$ & 1472 \\
$\begin{array}{l}\text { Right supramarginal } \\
\text { gyrus }\end{array}$ & $52-4028$ & $<0.001$ & 1553 \\
$\begin{array}{l}\text { Right superior temporal } \\
\text { gyrus }\end{array}$ & $58-4219$ & & \\
$\begin{array}{l}\text { Right angular gyrus } \\
\text { Right supplementary }\end{array}$ & $52-4936$ & & \\
$\quad$ motor area & 81748 & $<0.001$ & 1498 \\
$\begin{array}{l}\text { Right medial superior } \\
\quad \text { frontal gyrus }\end{array}$ & 84234 & & \\
$\begin{array}{l}\text { Right superior frontal } \\
\text { gyrus }\end{array}$ & 285416 & $<0.001$ & 891 \\
$\begin{array}{l}\text { Right middle frontal } \\
\text { gyrus }\end{array}$ & 265124 & & \\
Left caudate & -10116 & 0.017 & 314 \\
\hline
\end{tabular}

Table 4. Whole-brain cluster-level significant task regions during proactive response inhibition across levels (parametric regressors of Go),

\begin{tabular}{|c|c|c|c|}
\hline Region & $\begin{array}{l}\text { Peak MNI } \\
\text { coordinates }\end{array}$ & $\begin{array}{l}\mathrm{pFWE} \\
\text { value }\end{array}$ & $\begin{array}{l}\text { Number of } \\
\text { voxels in } \\
\text { cluster }\end{array}$ \\
\hline $\begin{array}{l}\text { Right superior temporal } \\
\text { gyrus }\end{array}$ & $51-3712$ & 0.011 & 248 \\
\hline Left insula & $-2826-6$ & 0.042 & 156 \\
\hline $\begin{array}{l}\text { Left inferior frontal } \\
\text { triangle }\end{array}$ & -32321 & & \\
\hline
\end{tabular}

Right middle cingulum, precentral and supramarginal gyrus signal increased after tyrosine administration compared with placebo (Fig. 8A; Table 6) $)_{n}$. We did not observe brain-behavior correlations between the effect of tyrosine on $\beta$ values in these regions and the effect of tyrosine on proactive slowing. Concurrent with the behavioral results, age modulated the effect of tyrosine on neural signal during proactive response inhibition (parametric regressors; Fig. 8B; Table 7)。. With increasing age, tyrosine decreased signal in bilateral putamen, left middle and superior frontal gyrus, right supramarginal gyrus and left precuneus relative to placebo (depicted for illustration purposes in Fig. 8C).

Several of these regions (i.e., those with age-dependent tyrosine-induced decreases in proactive signal) correlated positively with tyrosine's effect on behavioral RT slowing (Fig. 8D). Tyrosine-related decreases in fMRI signals were associated with tyrosine-related decreases in RT slowing in bilateral putamen (right: $r=0.51 p=0.01$; left: $r=0.41$ $p=0.046$ ), which was also marginally significant in left middle frontal gyrus $(r=0.40 p=0.054)_{\mathrm{p} 1,2,3}$.

In sum, tyrosine increased right middle cingulum, precentral and supramarginal gyrus signal during proactive response inhibition. With increasing age, tyrosine decreased fronto-striatal and parietal proactive signal. Of these regions showing detrimental effects of tyrosine administration with increasing age, bilateral putamen (and left middle frontal gyrus) demonstrated a relation with tyrosine's effect on behavior (i.e., proactive slowing). Moreover, with increasing age, tyrosine increased reactive signal in the angular gyrus. However, tyrosine effects in this reactive inhibition region did not show a relation with behavior.

\section{Effect of intervention on neuropsychological} measures and additional measures: catecholamine metabolites in urine, physiologic measures, and wellbeing

Tyrosine administration did not affect neuropsychological measures (Table 8), nor was there an interaction between age and the effect of tyrosine administration on these measures.

\section{Catecholamine metabolites in urine}

At the beginning of the test day (T0) as well as approximately $3 \mathrm{~h}$ after ingestion of tyrosine or placebo (T2), a urine sample was provided by the participants. As expected when consuming yoghurt after a night's fast, HVA, MOPEG, and VMA concentrations in urine were increased $\sim 3 \mathrm{~h}$ after ingestion of the mixture (T2) relative to the start of the test day (T0; main effects of time on HVA: $F_{(1,22)}=$ 20.98, $p<0.001$; MOPEG: $F_{(1,23)}=48.77, p<0.001$; VMA: $F_{(1,23)}=52.87, p<0.001$; Table 9 $)_{\mathrm{q}, \mathrm{r} 1 \mathrm{~s}}$.

Tyrosine administration affected catecholamine metabolites. VMA concentrations were lower after tyrosine compared with placebo (time $*$ intervention interaction, $F_{(1,23)}=$ $9.1, p=0.006$ ), driven by intervention differences in concentrations on T2 $\left(t_{(23)}=2.2, p=0.036\right)$, not T0 $\left(t_{(23)}=\right.$ $-0.078, p=0.94)_{r 2}$. However, DOPAC concentrations were higher after tyrosine compared with placebo (time * intervention interaction $F_{(1,22)}=8.8, p=0.007$ ), not driven 

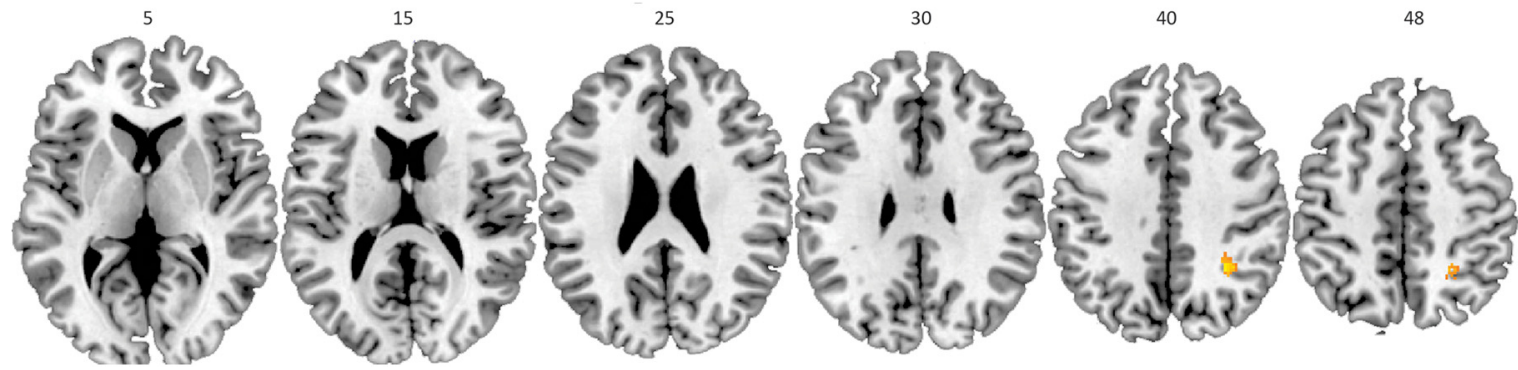

55

Figure 7. Positive correlation between age and effect of tyrosine on reactive response inhibition (StopSucces $>$ StopFailure). Images are thresholded at cluster-level significant extent threshold (pFWE $<0.05$; cluster-defining threshold: $p<0.001$, uncorrected). AAL labels, $p$ values, peak MNI coordinates, and number of voxels are listed in Table 5 . The position of the slices is labeled with the $z$ coordinates of the MNI atlas ${ }_{1, m}$.

by intervention effects on either T2 $\left(t_{(22)}=-0.43, p=\right.$ $0.67)$ or $\mathrm{TO}\left(t_{(23)}=1.3, p=0.2\right)_{\mathrm{t}}$.

Independent of intervention and time of measurement, VMA and DOPAC levels were modulated by age (main effect of age, VMA: $F_{(1,22)}=8.98, p=0.007$; DOPAC: $\left.F_{(1,21)}=5.5, p=0.024\right)_{\mathrm{u}, \mathrm{w}}$; increasing age was associated with higher urine levels of VMA and DOPAC. MOPEG and VMA levels interacted between time of measurement and age; increasing age was associated with a larger increase from time point T0 to T2 independent of tyrosine or placebo administration (MOPEG: $F_{(1,22)}=5.61, p=0.027$; VMA: $\left.F_{(1,22)}=4.92, p=0.037\right)_{\mathrm{u} 2, \mathrm{v}}$.

\section{Wellbeing, blood pressure, and heart rate}

Wellbeing ratings were assessed at the beginning of the test day (TO), at the assumed peak of tyrosine plasma level (T1) and at the end of the test day, $\sim 4 \mathrm{~h}$ after ingestion (T2). At the same time, systolic and diastolic blood pressure as well as heart rate were measured (Table 10).

Over the course of the test day, changes in wellbeing as measured on the Bond \& Lader total and contentness subscales were observed (main effect of time, total: $F_{(2,44)}=$ 4.00, $p=0.025$; contentness: $F_{(2,44)}=9.4, p<0.001$, respectively $)_{x, y}$. Wellbeing decreased on T1 compared with T0 (total: $F_{(1,23)}=8.6, p=0.008$; contentness: $F_{(1,23)}=$ $12.8, p=0.002)$, and increased to baseline again on T2 compared with T1 and T0 (T2 vs T1 total: $F_{(1,23)}=4.5, p=$ 0.045 and contentness: $F_{(1,23)}=10.53, p=0.004$, T2 vs T0 total: $F_{(1,23)}<1$ and contentness: $\left.F_{(1,23)}<1\right)$. The subscales calmness and alertness did not change over time. The effect of tyrosine on the Bond \& Lader subscale scores during the baseline corrected therapeutic window (T1 - T0) did not interact with age.

Systolic and diastolic blood pressure changed over the course of the test day (main effect of time systolic: $F_{(2,44)}=$

Table 5. Whole-brain cluster-level significant regions yielding a positive correlation between age and effect of tyrosine during reactive response inhibition (StopSuccess > StopFailure) $)_{1, m}$

\begin{tabular}{llll}
\hline & & & Number of \\
Region & Peak MNI & pFWE & voxels in \\
Right angular gyrus & $34-4940$ & 0.021 & 221
\end{tabular}

8.7, $p=0.001$ and diastolic: $\left.F_{(2,44)}=20.7, p<0.001\right)_{z \text {,aa. }}$. Diastolic pressure decreased on T1 compared with T0 $\left(F_{(1,23)}=18.1, p<0.001\right)$, and both systolic and diastolic blood pressure increased on T2 compared with T1 (systolic: $F_{(1,22)}=8.4, p=0.008$ and diastolic: $F_{(1,23)}=27.6$, $p<0.001)$. No effects of tyrosine administration or age were observed on systolic and diastolic blood pressure or heart rate during the baseline corrected therapeutic window (T1 - T0). Heart rate did not change over time.

The correlation between age and verbal IQ was nonsignificant $(r=-0.221, p=0.323)$. Verbal IQ was measured with the NART, which generally shows large cohort effects between age groups, with older adults performing better than younger adults (Uttl, 2002; see also unpublished observations from our lab (by $\mathrm{M}$ Bloemendaal, $\mathrm{E}$ Aarts, $M$ van Holstein, R Cools) using the equivalent version in the native language of the participants). Therefore, this provides some confirmation of our hypothesis that there is minimal influence of generational differences on the current results with our small age range.

\section{Discussion}

The current study investigated the neuro-cognitive effects of acute tyrosine administration, a dopamine precursor, on reactive and proactive response inhibition in a healthy older sample (aged 61-72 years; mean age: 67.5 ). Behaviorally, across the group, no effects of tyrosine administration on measures of reactive (i.e., SSRT) and proactive response inhibition (i.e., response slowing) were observed, although, neurally, proactive neural signal in right middle cingulum, precentral and supramarginal gyrus was increased by tyrosine. When taking age into account, age was found to negatively modulate the effect of tyrosine on proactive behavioral response slowing independent of cognitive load (i.e., level): increasing age was associated with a greater detrimental effect of tyrosine on proactive slowing compared with placebo. Functional imaging results were concomitant with the behavioral results: with increasing age, tyrosine decreased fronto-striatal and parietal proactive signal, but increased reactive signal in the angular gyrus. Brainbehavior correlations underline the behavioral relevance of modulated signal in these areas involved in proactive inhibition: tyrosine's effects on bilateral putamen (and left middle frontal gyrus) signal correlated positively with ty- 

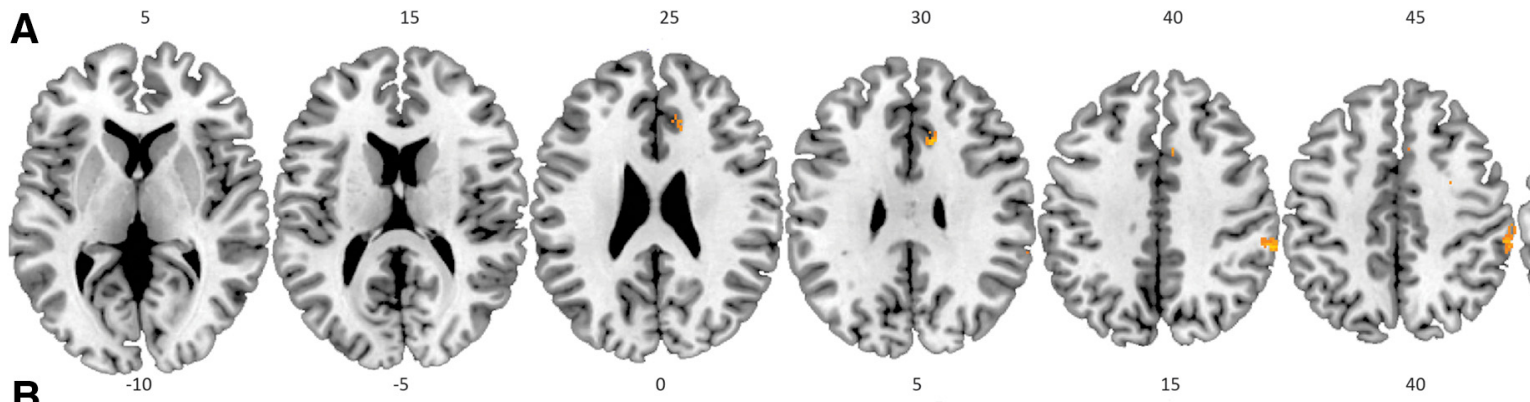

55
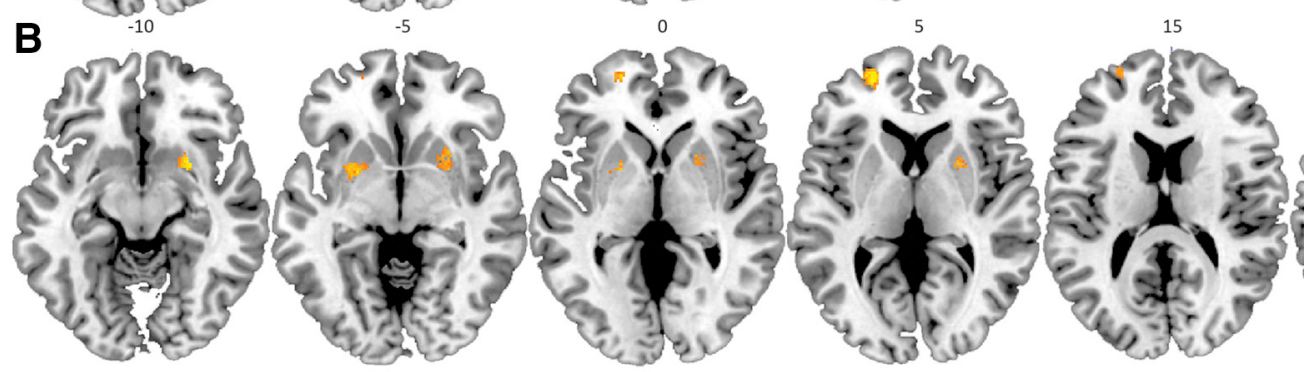

40

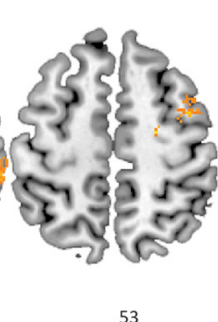

C
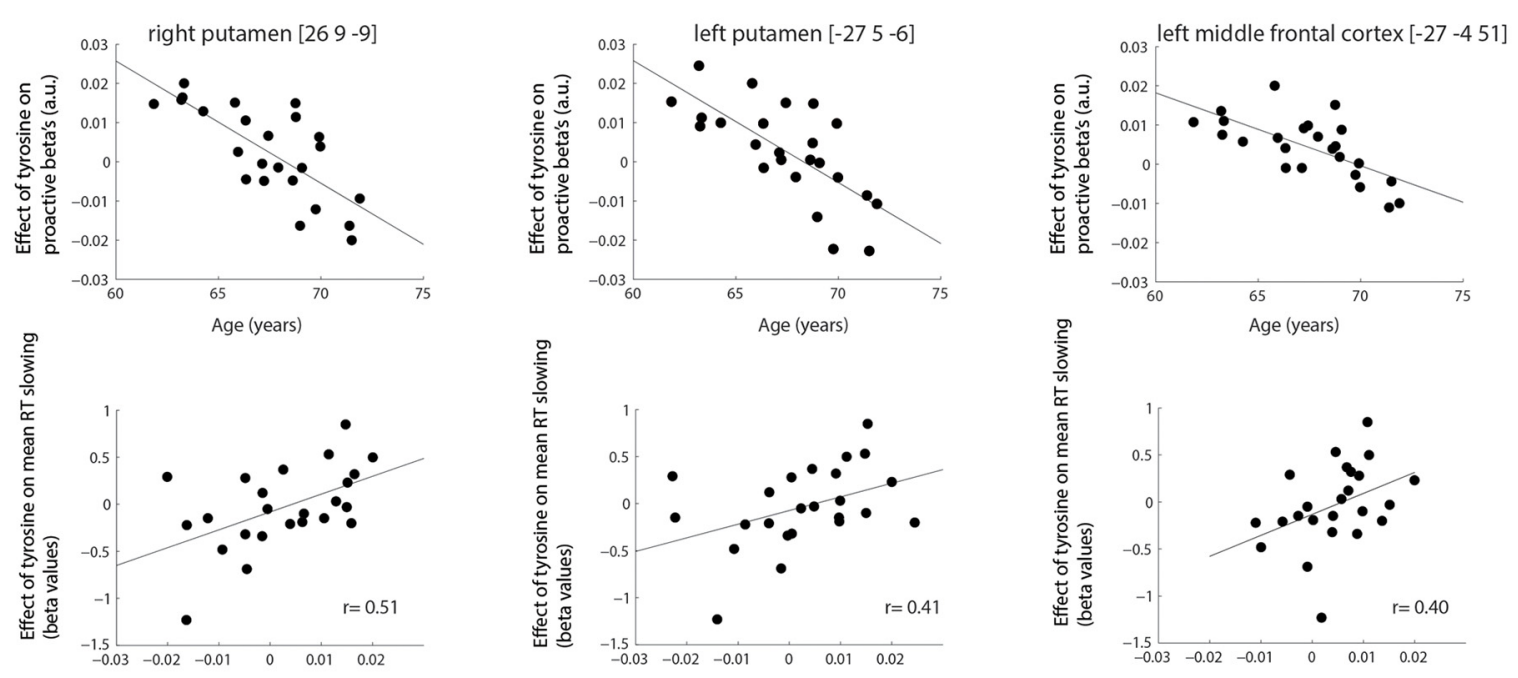

Figure 8. $\boldsymbol{A}$, Effect of tyrosine versus placebo during proactive response inhibition (parametric proactive regressor). Images are thresholded at cluster level significant extent threshold (pFWE $<0.05$ ). AAL labels, $p$ values, peak MNI coordinates, and number of voxels are listed in Table 6. B, Negative whole-brain correlation between age and effect of tyrosine on proactive response inhibition (parametric proactive regressor). Images are thresholded at cluster level significant extent threshold (pFWE $<0.05$ ); cluster-defining threshold: $p<0.001$, uncorrected). AAL labels, $p$ values, peak MNI coordinates, and number of voxels are listed in Table 7. $\boldsymbol{C}$, For illustration purposes, the negative correlation between proactive $\beta$ s and age is plotted for the regions showing a brain-behavior correlation (see below). $\boldsymbol{D}$, Regions with enhanced proactive signal after tyrosine with increasing age, correlated positively with tyrosine's effect on behavioral RT slowing. The position of the slices is labeled with the $z$ coordinates of the MNI atlas ${ }_{n, o, p}$.

rosine's effect on proactive slowing. Such brain-behavior correlations were not observed for reactive inhibition.

The age-dependent detrimental effects of tyrosine on proactive slowing are surprising given that prior work has shown almost exclusively beneficial effects of tyrosine administration on cognition (for review, see Jongkees et al., 2015). Critically, these prior studies have all assessed young, not older adults. A study in adult schizophrenia patients (mean age 37.8 years, SD 6.8) displayed increased errors in a smooth pursuit saccades task in eight patients during three weeks supplementation of 10-g tyrosine daily (Deutsch et al., 1994). In line with an overdose hypothesis, a recent study demonstrated decreased working memory (i.e., n-back) performance with

Table 6. Whole-brain cluster-level significant regions for tyrosine versus placebo during proactive response inhibition (parametric regressors) $n$

Region

Right middle cingulum

Right anterior cingulum

Right precentral gyrus

Right middle frontal gyrus

Right supramarginal gyrus

\begin{tabular}{|c|c|c|}
\hline $\begin{array}{l}\text { Peak MNI } \\
\text { coordinates }\end{array}$ & pFWE & $\begin{array}{l}\text { Number of } \\
\text { voxels in } \\
\text { cluster }\end{array}$ \\
\hline $\begin{array}{l}122031 \\
123221\end{array}$ & 0.006 & 229 \\
\hline $\begin{array}{l}26-1254 \\
40055\end{array}$ & 0.006 & 233 \\
\hline $61-3442$ & 0.014 & 197 \\
\hline
\end{tabular}


Table 7. Whole-brain cluster-level significant regions yielding a negative correlation between age and effect of tyrosine during proactive response inhibition (parametric regressors)。

\begin{tabular}{llcl}
\hline & $\begin{array}{l}\text { Peak MNI } \\
\text { coordinates }\end{array}$ & $\begin{array}{l}\text { pFWE } \\
\text { value }\end{array}$ & $\begin{array}{l}\text { Number of } \\
\text { voxels in } \\
\text { cluster }\end{array}$ \\
Region & $269-9$ & 0.001 & 291 \\
Right putamen & $-27-451$ & 0.041 & 103 \\
Left middle frontal gyrus & $-34-654$ & & \\
Left precentral gyrus & -22574 & $<0.001$ & 356 \\
Left superior frontal gyrus & -22450 & & \\
Left middle frontal gyrus & -24507 & 0.019 & 175 \\
Right supramarginal gyrus & $62-2827$ & 0.034 & 153 \\
Left putamen & $-275-6$ & 0.049 & 141 \\
Left precuneus & $-3-6142$ & 0.04 &
\end{tabular}

increasing tyrosine dose (from 100-150 to $200 \mathrm{mg} / \mathrm{kg}$ ) in older adults (aged 60-75 years, mean age: 69.6; van de Rest et al., 2017). This cognitive overdose effect of tyrosine, which has so far been observed only in older adults, may be at least partly caused by a larger effective dose in older adults due to increased peripheral supply of tyrosine. Earlier research demonstrated increased plasma tyrosine levels in fasting older versus young women (Caballero et al., 1991) and increased plasma response in older versus young adults receiving the same dose (van de Rest et al., 2017). Critically, in this latter study, dosedependent increases in plasma response correlated with dose-dependent decrements in working memory after tyrosine ingestion. Several peripheral processes can cause this presumed enhanced bioavailability; for example an age-related reduced first pass effect in the liver (Klotz, 2009), may result in higher amounts of tyrosine entering the blood stream in older adults. Furthermore, age-related insulin resistance (Caballero et al., 1991) may contribute to reduced peripheral amino acid uptake from the blood, resulting in higher amounts that reach the blood-brain barrier. The current results cannot identify the cause of enhanced bioavailability, which should be further studied. Results from the current study in urine metabolites support the idea of increased peripheral catecholamine precursor levels in older adults. Irrespective of intervention, we observed higher amounts of VMA and

Table 8. Effect of intervention on stop-signal task and neuropsychological tests $\mathrm{a}_{\mathrm{a}, \mathrm{b}}$

\begin{tabular}{|c|c|c|c|c|}
\hline Variable & Placebo & Tyrosine & $p$ value & $p$ value age \\
\hline Story immediate recall (points) & $9.5(0.6)$ & $10.2(0.7)$ & 0.3 & 0.68 \\
\hline Story delayed recall (points) & $9.0(0.6)$ & $9.2(0.6)$ & 0.8 & 0.47 \\
\hline Digit span forward (points) & $7.5(0.4)$ & $7.21(0.4)$ & 0.14 & 0.75 \\
\hline Digit span backward (points) & $6.1(0.4)$ & $6.25(0.5)$ & 0.84 & 0.93 \\
\hline Stroop effect (s) & $81.4(11.1)$ & $95.88(12.5)$ & 0.18 & 0.38 \\
\hline Stroop effect (errors) & $.7(0.2)$ & $1.32(0.3)$ & 0.14 & 0.43 \\
\hline Verbal fluency DAT (items) & $45.26(2.3)$ & $44.13(2.3)$ & 0.8 & 0.09 \\
\hline Block completion & $92.23(7.83)$ & $83.42(4.17)$ & 0.36 & 0.84 \\
\hline Letter cancellation & $249.29(7.07)$ & 250.17 (7.39) & 0.61 & 0.35 \\
\hline
\end{tabular}

Data represent mean (SEM). The first column with $p$ values reflect the outcome of the paired $t$ tests between tyrosine and placebo on the behavioral measure, the second column with $p$ values reflects the interaction between tyrosine's effect on the behavioral measure and age.

Table 9. Effect of tyrosine administration on catecholamine metabolites in urine $\mathrm{q}_{\mathrm{q}, \mathrm{r}, \mathrm{s}, \mathrm{t}, \mathrm{u}, \mathrm{v}, \mathrm{w}}$

\begin{tabular}{|c|c|c|c|c|c|}
\hline Variable & Placebo & & Tyrosine & & \\
\hline (mmol/M kr) & TO & T2 & TO & T2 & $p$ value \\
\hline HVA & $2.80(0.22)$ & $3.36(0.30)$ & $2.74(0.24)$ & $3.20(0.25)$ & 0.43 \\
\hline MOPEG & $1.08(0.06)$ & $1.34(0.06)$ & $1.14(0.07)$ & $1.3(0.07)$ & 0.097 \\
\hline VMA & $1.75(0.11)$ & $2.1(0.12)$ & $1.75(0.1)$ & $2.0(0.12)$ & 0.006 \\
\hline DOPAC & $1.21(0.11)$ & $1.25(0.13)$ & $1.10(0.1)$ & $1.28(0.12)$ & 0.013 \\
\hline
\end{tabular}

Metabolite concentrations are expressed in $\mathrm{mmol} / \mathrm{mol}$ creatinine, to correct for sample volume; $p$ values reflect the interaction between drug and time from the ANOVA on tyrosine administration (tyrosine, placebo) and time (T0, T2). The effect of tyrosine on catecholamine metabolites did not interact with age.

Table 10. Wellbeing scales, blood pressure, and heart rate $\mathrm{x}_{\mathbf{x}, \mathbf{z}, \mathbf{a}, \mathrm{a}}$

\begin{tabular}{|c|c|c|c|c|c|c|c|}
\hline \multirow[t]{2}{*}{ Variable } & \multicolumn{3}{|l|}{ Placebo } & \multicolumn{3}{|l|}{ Tyrosine } & \multirow[t]{2}{*}{$p$ value } \\
\hline & T0 & $\mathrm{T} 1$ & T2 & T0 & $\mathrm{T} 1$ & $\mathrm{~T} 2$ & \\
\hline B\&L total & $8.1(0.3)$ & $7.7(0.3)$ & $8.1(0.3)$ & $8.0(0.2)$ & $7.6(0.4)$ & $8.0(0.3)$ & 0.97 \\
\hline B\&L calmness & $7.7(0.4)$ & $7.2(0.5)$ & $7.7(0.4)$ & $8.1(0.3)$ & $7.3(0.5)$ & $7.6(0.4)$ & 0.58 \\
\hline B\&L contentness & $8.4(0.25)$ & $7.6(0.4)$ & $8.5(0.3)$ & $8.3(0.2)$ & $7.6(0.4)$ & $8.3(0.3)$ & 0.99 \\
\hline B\&L alertness & $8.0(0.3)$ & $7.8(0.4)$ & $8.1(0.3)$ & $7.9(0.3)$ & $7.6(0.3)$ & $8.0(0.3)$ & 0.96 \\
\hline Systolic blood pressure & $136.0(3.8)$ & 140. (4.0) & $143.3(3.8)$ & $137.8(3.8)$ & $136.7(3.5)$ & $145.9(4.4)$ & 0.06 \\
\hline Diastolic blood pressure & $84.0(1.7)$ & $80.8(2.1)$ & $85.71(1.8)$ & $82.8(1.8)$ & $80.0(1.8)$ & $87.2(1.8)$ & 0.72 \\
\hline Heart rate & $63.4(1.8)$ & $63.6(1.7)$ & $61.2(1.4)$ & $63.4(1.7)$ & $63.2(1.5)$ & $62.7(1.6)$ & 0.72 \\
\hline
\end{tabular}

B\&L, Bond \& Lader; $p$ values reflect the outcome of the paired $t$ tests between tyrosine and placebo on the baseline corrected physiologic measure (T1 - T0). No interactions between tyrosine administration and time or age were observed. 
Table 11. Summary of statistical analyses

Data structure

Behavioral results

Reactive response inhibition

Interaction between intervention and level on reactive response inhibition (SSRT)

Effect of intervention on reactive response inhibition (SSRT)

Interaction between intervention and covariate age on reactive response inhibition (SSRT)

Main effect of age on reactive response inhibition (SSRT)

Proactive response inhibition

Interaction between intervention and level $(\mathrm{B}, \mathrm{C})$ on proactive slowing $\beta \mathrm{s}$

Effect of intervention on proactive slowing $\beta$ s

Interaction between intervention and covariate age on proactive slowing $\beta$ s

Main effect of intervention on proactive slowing $\beta$ s

Interaction between intervention effect and order on proactive slowing $\beta$ s

fMRI results

Reactive and proactive response inhibition task effects

Task effects on reactive response inhibition across intervention and level (contrasts StopSuccess vs Failure and StopSuccess vs Go)

Task effects on proactive response inhibition across intervention and level

Intervention effects on reactive response inhibition (contrasts StopSuccess vs Failure and StopSuccess vs Go)

Effect on intervention across levels on reactive response inhibition

Interaction between intervention (difference between tyrosine and placebo) and covariate age on reactive response inhibition

Intervention effects on proactive response inhibition

Effect on intervention on proactive response inhibition Interaction between intervention (difference between tyrosine and placebo) and covariate age on proactive response inhibition

Brain-behavior correlations between functional $\beta$ s showing detrimental effects of tyrosine administration with increasing age and behavioral intervention effect

(on proactive slowing $\beta \mathrm{s}$ )

\section{Additional measures}

Catecholamine metabolites in urine

Main effect of time on HVA

Main effect of time on VMA

Time (TO, T2) * intervention interaction on VMA

main effect of time on MOPEG

Time (TO, T2) * intervention interaction on DOPAC

Main effect of age on VMA

Intervention $*$ age interaction on VMA

Intervention $*$ age interaction on MOPEG

Main effect of age on DOPAC

Wellbeing, blood pressure, and heart rate

Main effect of time on B\&L total

Main effect of time on B\&L contentness

Main effect of time on systolic blood pressure

Main effect of time on diastolic blood pressure
Type of test

Statistic

a1. RM ANOVA

a2. RM ANOVA

b1. RM ANOVA with coviarate age

b2. RM ANOVA with coviarate age

c. RM ANOVA

d. RM ANOVA

e1. RM ANOVA with coviarate age

2. RM ANOVA with coviarate age f. RM ANOVA with coviarate age and order

$\mathrm{g}$, h. one sampled $t$ test

i. one sampled $t$ test

j, k. paired $t$ test

I, m. one-way ANOVA with covariate age

n. paired $t$ test

o. one-way ANOVA with covariate age

p1. correlation

p2

p3

\section{q. RM ANOVA \\ r1. RM ANOVA \\ r2. RM ANOVA \\ s. RM ANOVA \\ t. RM ANOVA}

u1. RM ANOVA with covariate age u2. RM ANOVA with covariate age v. RM ANOVA with covariate age w. RM ANOVA with covariate age

x. RM ANOVA

y. RM ANOVA

z. RM ANOVA

aa. RM ANOVA

Table 4

Table 6

Table 7
$\mathrm{Cl}$ for the difference of intervention effect (unless otherwise specified)

$F_{(2,46)}=1.19, p=0.31, \eta_{p}^{2}=0.05$

$F_{(1,23)}=0.007, p=0.93, \eta_{p}^{2}=0.00$

$-3.87 / 3.57$

$F_{(1,22)}=0.002, p=0.95, \eta_{p}^{2}=0.00$

$-3.961 / 3.66$

$F_{(1,22)}=4.3, p=0.05, \eta_{p}^{2}=0.16$

$F_{(1,23)}=0.11, p=0.739, \eta_{p}^{2}=0.01$

$F_{(1,23)}=1.55, p=0.68, \eta_{p}^{2}=0.01$

$F_{(1,22)}=5.7, p=0.026, \eta_{p}^{2}=0.21$

$-0.22 / .15$

$-0.20 / 0.13$

$F_{(1,22)}=5.6, p=0.027, \eta_{p}^{2}=0.20$

$F_{(1,21)}=2.4, p=0.136, \eta_{p}^{2}=0.10$

$-0.20 / 0.13$

Tables 2, 3

pFWE $<0.05$, no significant clusters

For contrast StopSuccess vs Failure, see Table 5 ; contrast StopSuccess vs Go, no significant results at $\mathrm{pFWE}<0.05$

Left middle frontal gyrus $(r=0.40, p=0.054$

$0.01 / 0.70$

Bilateral putamen (right: $r=0.51, p=0.01$ )

$0.13 / 0.76$

$0.01 / 0.70$

$F_{(1,22)}=20.98, p=0.001$

$F_{(1,23)}=52.87, p=0.000$

$F_{(1,23)}=9.1, p=0.006$

T2: $t_{(23)}=2.2, p=0.036$;

T0: $t_{(23)}=-0.078, p=0.94$

$F_{(1,23)}=48.77, p=0.000$

$F_{(1,22)}=8.8, p=0.007$

T2: $t_{(22)}=-0.43, p=0.67$

T0: $t_{(23)}=1.3, p=0.2$

$F_{(1,22)}=8.98, p=0.007$

$F_{(1,22)}=4.92, p=0.037$

$F_{(1,22)}=5.61, p=0.027$

$F_{(1,21)}=5.5, p=0.024$

$F_{(2,44)}=4.00, p=0.03$

T1 vs T0: $F_{(1,23)}=8.6, p=0.01$;

T2 vs T1: $F_{(1,23)}=4.5, p=0.05$;

T2 vs T0 total: $F_{(1,23)}<1$

$F_{(2,44)}=9.4, p<0.001$

T1 vs T0: $F_{(1,23)}=12.8, p=0.002$;

T2 vs T1: $F_{(1,23)}=10.53, p=0.004$

T2 vs T0 total: $F_{(1,23)}<1$

$F_{(2,44)}=8.7, p=0.001$

T1 vs T0: $F_{(1,23)}=18.1, p<0.001$;

T2 vs T1: $F_{(1,22)}=8.4, p=0.008$

$F_{(2,44)}=20.7, p<0.001$

T2 vs T1: $F_{(1,23)}=27.6, p=0.000$
T0 vs T2: $-0.52 / 0.20$

T0 vs T2: $-0.14 / 0.03$

T0 vs T2: $-0.27 /-0.15$

$-0.24 / 0.010$

$1.68 / 2.07$

$-0.06 / 0.08$

T1 vs T0: $-0.075 / \mathrm{T} 2$ vs

T1: $0.82,-0.99 / 0.16$

T2 vs T0: $-0.44 / 0.37$

T1 vs T0: $-0.08 / 0.82$

T2 vs T1: $-0.99 / 0.16$

T2 vs T0: $-0.44 / 0.37$

T1 vs T0: $-4.31 / 1.44$

T2 vs T1: $-10.77 /-0.62$

T2 vs T1: $-8.56 /-2.90$

B\&L, Bond \& Lader. 
DOPAC across time and a higher increase of MOPEG and VMA metabolites with time, as a function of age. Thus, increased peripheral supply of tyrosine to the blood-brain barrier might have resulted in the currently observed agedependent overdose effects on proactive response inhibition, despite the same oral dose per kilogram of bodyweight in every participant and despite increased dopamine deficits with aging.

Mechanistically, the conversion of tyrosine to L-dopa by the rate-limiting enzyme $\mathrm{TH}$ is inhibited by its final end products, i.e., the catecholamines dopamine and noradrenaline, present in the cytoplasm (Daubner et al., 2011). Indeed, a very high dose of phenylalanine, the conditional precursor of tyrosine, reduced dopamine release in the rat striatum, whereas lower doses increased dopamine release (During et al., 1988). The authors speculated that $\mathrm{TH}$ inhibition resulted in net reduced dopamine synthesis due to sudden high amounts of cytoplasmic catecholamines. Reduction of dopamine synthesis by inhibiting TH may also occur further in the dopamine signaling cascade, when an excess of dopamine increases dopamine D2 autoreceptor binding (Lindgren et al., 2001). The aging brain might be more sensitive to overshoots in auto-regulation, for example due to increased inflammatory markers, such as cytokines, which increase with age (Michaud et al., 2013) and can alter TH availability and auto-regulatory dopamine transporter expression (Felger and Miller, 2012).

Detrimental effects of tyrosine may be less surprising when considering literature on increased dopamine synthesis capacity in older adults, which is consistently observed when using the PET tracer FMT (Dejesus et al., 2001; Braskie et al., 2008; Berry et al., 2016), although mixed results have been obtained with another aromatic amino acid decarboxylase substrate, FDOPA, with decreased signal-to-noise (Martin et al., 1989; Sawle et al., 1990; Bhatt, 1991; Dreher et al., 2008). Increased agerelated dopamine synthesis was negatively correlated with reward-related BOLD signal (Dreher et al., 2008) and, similarly, the positive relation between dopamine synthesis and cognitive performance seen in young adults was absent in older adults (Berry et al., 2016). We speculate that administrating extra precursor to a system with already high dopamine synthesis capacity may result in its inhibition.

The current results provide a first indication of agerelated effects of tyrosine administration on dopamine processing. We used age as a continuous measure to assess its relation to tyrosine's effects on neurocognition. However, looking at the scatter plots, it seems that the detrimental effects of tyrosine administration on proactive inhibitory responses in brain and behavior were especially apparent in the middle-old, sometimes referred to as old-old, group (70-79 years) relative to the young-old (60-69 years) participants. This is in accordance with the sub-group definition by some authors (Forman et al., 1992; de Almondes et al., 2016), although others have defined young-old individuals as 65-74 years old (Zizza et al., 2009; Moon et al., 2018) . In either definition, most of our participants were in the young-old group. However, age-related changes in the dopamine system have already been observed in similar age groups as in the current study, e.g., dopamine receptor binding differences in individuals up to 68 years old (Bäckman et al., 2000) and increased dopamine synthesis capacity in a group of older adults of on average 67 years old (Braskie et al., 2008). Nevertheless, previous dopamine findings were obtained by contrasting the effects between individuals with larger age differences than in the current study, although linear effects on striatal dopamine receptor binding with increasing age can be observed among the few participants that were in our age range of 61-72 years old (Wang et al., 1998). To strengthen our results, the peripheral and central mechanisms underlying age-dependent tyrosine effects on cognition should be investigated in future studies with larger age ranges and sample sizes, including measures of dopamine functioning. Moreover, the current results should be replicated using longitudinal designs, as cross-sectional designs cannot easily control for between-subject differences other than age, which could have contributed to the current results; even in this small age range.

Previous studies that have used $150 \mathrm{mg} / \mathrm{kg}$, similar to the current study, have observed positive effects of tyrosine administration on cognition in young adults (Jongkees et al., 2015). However, it must be noted that these studies subjected participants to a stress intervention such as acoustic noise or a cold bath. One study did not use an external stress intervention other than the task at hand (Thomas et al., 1999) and only found positive effects of $150 \mathrm{mg} / \mathrm{kg}$ tyrosine administration on demanding multitasking. Stress or demanding circumstances increase neuronal firing and thereby catecholamine metabolism (Bliss et al., 1968), making these neurons more sensitive to precursor availability such as tyrosine (Scally et al., 1977). For this reason, a relatively high dose may be optimal in a high neuronal firing situation, but suboptimal during basal neuronal firing, even in young adults.

Effects of tyrosine administration were most prominent on behavioral and neural measures of proactive response inhibition. Behaviorally, with increasing age, tyrosine modulated only proactive response slowing, not SSRT. Neurally, tyrosine modulated signal in fronto-striatal and parietal regions during proactive inhibition, which was associated with its behavioral effects. Previous studies found evidence for dopaminergic modulation of proactive-like processes in response inhibition (such as post-error slowing and go accuracy; Bari et al., 2009; Bari and Robbins, 2013), without formally disentangling proactive and reactive response inhibition as in the current paradigm. Moreover, we show age-dependent effects of tyrosine on proactive response inhibition in, among others, bilateral putamen. The putamen was also found to be modulated by Go trial probability in a study by Dunovan et al. (2015), as well as in a network uniquely active during proactive response inhibition, as determined using independent component analysis (van Belle et al., 2014). These observations strengthen the interpretation that tyrosine has selectively modulated a functional network uniquely involved in processing proactive cues. 
With noradrenaline being produced from dopamine, tyrosine administration could potentially also have contributed to increased noradrenaline synthesis. We cannot fully exclude this possibility, but given the presently observed tyrosine modulation of signal in the putamen, which is highly innervated by dopamine rather than noradrenaline (Nicola and Malenka, 1998), we hypothesize that the currently observed tyrosine effects are driven by dopaminergic neurons. Our hypothesis is strengthened by literature stating shortage of especially dopamine in the aging brain (Finch, 1973; Ota et al., 2006), rather than noradrenaline (Goldman-Rakic and Brown, 1981; Moretti et al., 1987).

During reactive response inhibition, tyrosine modulated angular gyrus signal with increasing age, which is only scarcely innervated by dopamine. Moreover, no behavioral effect of tyrosine on SSRT was observed, neither a correlation between tyrosine's effect on this reactive region and SSRT. Therefore, the observed decrease in angular gyrus activation after tyrosine with increasing age might well reflect either an indirect result of tyrosine's fronto-striatal effects on proactive inhibition or a noradrenergic effect in combination with a floor effect in SSRTs.

The majority of the catecholamine metabolites increased to a lesser extent after tyrosine compared with placebo administration (VMA significantly and MOPEG and HVA numerically). Only DOPAC levels increased after tyrosine compared with placebo. However, for unknown reasons, large baseline (T0) differences between intervention sessions were observed on this measure. This complicates the interpretation of the intervention effect on DOPAC levels. These mixed results should generally be interpreted with caution, as urine measures mostly reflect peripheral instead of central metabolites, with no clear link with central dopamine levels (Chekhonin et al., 2000).

In conclusion, we show age-related effects of tyrosine administration especially on proactive, not reactive, response inhibition, accompanied by signal changes in dopamine-rich fronto-striatal brain regions. Specifically, we observed that tyrosine's effect on brain and cognition became detrimental with increasing age, questioning the cognitive enhancing potential of tyrosine in healthy aging.

Our results, particularly those in striatum, provide support for the hypothesis that proactive, but not reactive, response inhibition is modulated by dopamine.

\section{References}

Ashburner J (2007) A fast diffeomorphic image registration algorithm. Neurolmage, 38(1), 95-113. CrossRef

Bäckman L, Ginovart N, Dixon RA, Wahlin T-BR, Wahlin A, Halldin C, Farde $L$ (2000) Age-related cognitive deficits mediated by changes in the striatal dopamine system. Am J Psychiatry 157:635-637. CrossRef

Bäckman L, Nyberg L, Lindenberger U, Li S, Farde L (2006) The correlative triad among aging, dopamine, and cognition: current status and future prospects. Neurosci Biobehav Rev 30:791-807. CrossRef

Banderet LE, Lieberman HR (1989) Treatment with tyrosine, a neurotransmitter precursor, reduces environmental stress in humans. Brain Res Bull 22:759-762. CrossRef

Bari A, Robbins TW (2013) Noradrenergic versus dopaminergic modulation of impulsivity, attention and monitoring behaviour in rats performing the stop-signal task: possible relevance to ADHD. Psychopharmacology (Berl) 230:89-111. CrossRef Medline

Bari A, Eagle DM, Mar AC, Robinson ESJ, Robbins TW (2009) Dissociable effects of noradrenaline, dopamine, and serotonin uptake blockade on stop task performance in rats. Psychopharmacology (Berl) 205:273-283. CrossRef

Bari A, Mar AC, Theobald DE, Elands SA, Oganya KC, Eagle DM, Robbins TW (2011) Prefrontal and monoaminergic contributions to stop-signal task performance in rats. J Neurosci 31:9254-9263. CrossRef

Basile-Filho A, Beaumier L, El-Khoury AE, Yu YM, Kenneway M, Gleason RE, Young VR (1998) Twenty-four-hour L-[1-13C]tyrosine and $\mathrm{L}-[3,3-2 \mathrm{H} 2]$ phenylalanine oral tracer studies at generous, intermediate, and low phenylalanine intakes to estimate aromatic amino acid requirements in adults. Am J Clin Nutr 67:640-659. CrossRef

Bedard A, Nichols S, Jose A, Schachar R, Logan GD, Tannock R (2002) The development of selective inhibitory control across the life span. Dev Neuropsychol 21:93-111. CrossRef

Berry AS, Shah VD, Baker SL, Vogel JW, O’Neil JP, Janabi M, Schwimmer HD, Marks SM, Jagust WJ (2016) Aging affects dopaminergic neural mechanisms of cognitive flexibility. J Neurosci 36:12559-12569.

Bhatt MH (1991) Positron emission tomography suggests that the rate of progression of idiopathic parktnsonism is slow. Ann Neurol 673-677. CrossRef

Bjelland I, Dahl AA, Haug TT, Neckelmann D (2002) The validity of the hospital anxiety and depression scale. An updated literature review. J Psychosom Res 52:69-77. CrossRef

Bliss EL, Ailion J, Zwanziger J (1968) Metabolism of norepinephrine, serotin and dopmaine in rat brain with stress. J Pharmacol Exp Ther 164:471-483.

Bloemendaal M, Zandbelt B, Wegman J, van de Rest O, Cools R, Aarts $E$ (2016) Contrasting neural effects of aging on proactive and reactive response inhibition. Neurobiol Aging 46:96-106. CrossRef

Boehler C, Bunzeck N, Krebs R, Noesselt T, Schoenfeld M, Heinze HJ, Münte T, Woldorff M, Hopf J (2011) Substantia nigra activity level predicts trial-to-trial adjustments in cognitive control. J Cogn Neurosci 23:362-373. CrossRef

Bond A, Lader M (1974) The use of analogue scales in rating subjective feelings. Br J Med Physiol 47:211-218. CrossRef

Braskie MN, Wilcox CE, Landau SM, O’Neil JP, Baker SL, Madison CM, Kluth JT, Jagust WJ (2008) Relationship of striatal dopamine synthesis capacity to age and cognition. J Neurosci 28:1432014328.

Caballero B, Gleason RE, Wurtman RJ (1991) Plasma amino acid concentrations in healthy elderly men and women. Am J Clin Nutr 53:1249-1252. CrossRef Medline

Cai JX, Arnsten AF (1997) Dose-dependent effects of the dopamine D1 receptor agonists A77636 or SKF81297 on spatial working memory in aged monkeys. J Pharmacol Exp Ther 283:183-189.

Chekhonin VP, Baklaushev VP, Kogan BM, Savchenko EA, Lebedev SV, Man'kovskaya IV, Filatova TS, Yusupova IU, Dmitrieva TB (2000) Catecholamines and their metabolites in the brain and urine of rats with experimental Parkinson's disease. Bull Exp Biol Med 130:805-809. CrossRef

Chowdhury R, Guitart-Masip M, Bunzeck N, Dolan RJ, Düzel E (2012) Dopamine modulates episodic memory persistence in old age. J Neurosci 32:14193-14204.

Chowdhury R, Guitart-Masip M, Lambert C, Dayan P, Huys Q, Düzel E, Dolan RJ (2013) Dopamine restores reward prediction errors in old age. Nat Neurosci 16:648-653. CrossRef

Colzato LS, Jongkees BJ, Sellaro R, Hommel B (2013) Working memory reloaded: tyrosine repletes updating in the $\mathrm{N}$-back task. Front Behav Neurosci 7:200. CrossRef

Colzato LS, De Haan AM, Hommel B (2014a) Food for creativity: tyrosine promotes deep thinking. Psychol Res 79:709-714. CrossRef 
Colzato LS, Jongkees BJ, Sellaro R, van den Wildenberg WPM, Hommel B (2014b) Eating to stop: tyrosine supplementation enhances inhibitory control but not response execution. Neuropsychologia 62:398-402.

Congdon E, Constable RT, Lesch KP, Canli T (2009) Influence of SLC6A3 and COMT variation on neural activation during response inhibition. Biol Psychol 81:144-152.

Daubner SC, Le T, Wang S (2011) Tyrosine hydroxylase and regulation of dopamine synthesis. Arch Biochem Biophys 508:1-12. CrossRef

de Almondes KM, Costa MV, Malloy-Diniz LF, Diniz BS (2016) The relationship between sleep complaints, depression, and executive functions on older adults. Front Psychol 7:1547. CrossRef

Deijen JB (2005) Tyrosine. In: Nutrition brain and behavior (Lieberman HR, Kanarek RB, Prasad C, eds), pp 363-381. Boca Raton, FL: CRC Press.

Dejesus OT, Endres CJ, Shelton SE, Nickles RJ, Holden JE (2001) Noninvasive assessment of aromatic L-amino acid decarboxylase activity in aging rhesus monkey brain in vivo. Synapse 39:58-63. CrossRef

Deutsch S, Rosse R, Schwartz B, Banay-Schwartz M, McCarthy M, Johri S (1994) L-tyrosine pharmacotherapy of schizophrenia: preliminary data. Clin Neuropharmacol 17:53-62. CrossRef

Dreher J-C, Meyer-Lindenberg A, Kohn P, Berman KF (2008) Agerelated changes in midbrain dopaminergic regulation of the human reward system. Proc Natl Acad Sci USA 105:15106-15111. CrossRef

Dunovan K, Lynch B, Molesworth T, Verstynen T (2015) Competing basal ganglia pathways determine the difference between stopping and deciding not to go. eLife, 4(September 2015), 1-24. CrossRef

During MJ, Acworth IN, Wurtman RJ (1988) Phenylalanine administration influences dopamine release in the rat's corpus striatum. Neurosci Lett 93:91-95. CrossRef

Eagle DM, Baunez C (2010) Is there an inhibitory-response-control system in the rat? Evidence from anatomical and pharmacological studies of behavioral inhibition. Neurosci Biobehav Rev 34:50-72. CrossRef [Medline]

Eagle DM, Tufft MRA, Goodchild HL, Robbins TW (2007) Differential effects of modafinil and methylphenidate on stop-signal reaction time task performance in the rat, and interactions with the dopamine receptor antagonist cis-flupenthixol. Psychopharmacology (Berl) 192:193-206. CrossRef

Eagle DM, Bari A, Robbins TW (2008) The neuropsychopharmacology of action inhibition: cross-species translation of the stopsignal and go/no-go tasks. Psychopharmacology (Berl) 199:439456. CrossRef

EFSA Panel on Dietetic Products Nutrition and Allergies (2011) Scientific opinion on the substantiation of health claims related to L-tyrosine and contribution to normal synthesis of catecholamines (ID 1928), increased attention (ID 440, 1672, 1930), and contribution to normal muscle function (ID 1929) pursua. EFSA J 9:1-16. CrossRef

Felger JC, Miller AH (2012) Cytokine effects on the basal ganglia and dopamine function: the subcortical source of inflammatory malaise. Front Neuroendocrinol 33:315-327. CrossRef Medline

Fernstrom JD, Wurtman RJ, Hammarstrom-Wiklund B, Rand WM, Munro HN, Davidson CS (1979) Diurnal variations in plasma concentrations of tryptophan, tyrosine, and other neutral amino acids: effect of dietary protein intake. Am J Cin Nutr 32:1912-1922. CrossRef

Finch CE (1973) Catecholamine metabolism in the brains of ageing male mice. Brain Res 52:261-276. Medline

Folstein M, Folstein S, McHugh P (1975) "Mini-mental state". A practical method for grading the cognitive state of patients for the clinician. J Psychiat Res 12:189-198. Medline

Forman DE, Berman AD, McCabe CH, Baim DS, Wei JY (1992) PTCA in the elderly: the "young-old" versus the "old-old." J Am Geriatr Soc 40:19-22. CrossRef
Gazzaley A, Clapp W, Kelley J, McEvoy K, Knight RT, D'Esposito M (2008) Age-related top-down suppression deficit in the early stages of cortical visual memory processing. Proc Natl Acad Sci USA 105:13122-13126. CrossRef

Ghahremani DG, Lee B, Robertson CL, Tabibnia G, Morgan AT, De Shetler N, Brown AK, Monterosso JR, Aron AR, Mandelkern MA, Poldrack RA, London ED (2012) Striatal dopamine D2/D3 receptors mediate response inhibition and related activity in frontostriatal neural circuitry in humans. J Neurosci 32:7316-7324. CrossRef

Glaeser BS, Melamed E, Growdon JH, Wurtman RJ (1979) Elevation of plasma tyrosine after a single oral dose of I-tyrosine. Life Sci 25:265-271. Medline

Glaeser BS, Maher TJ, Wurtman RJ (1983) Changes in brain levels of acidic, basic, and neutral amino acids after consumption of single meals containing various proportions of protein. J Neurochem 41:1016-1021.

Goldman-Rakic PS, Brown RM (1981) Regional changes of monoamines in cerebral cortex and subcortical structures of aging rhesus monkeys. Neuroscience 6:177-187. CrossRef

Growdon JH, Melamed E, Logue M, Hefti F, Wurtman RJ (1982) Effects of oral L-tyrosine administration on CSF tyrosine and homovallinic acid levels in patients with Parkinson's disease. Life Sci 30:827-832. CrossRef

Grubbs F (1969) Procedures for detecting outlying observations in samples. Technometrics 11:1-21. CrossRef

Healey M, Campbell KL, Hasher L (2008) Cognitive aging and increased distractibility: costs and potential benefits. Prog Brain Res 169: 353-363.

Jongkees BJ, Hommel B, Kühn S, Colzato LS (2015) Effect of tyrosine supplementation on clinical and healthy populations under stress or cognitive demands--A review. J Psychiatr Res 70: 50-57. CrossRef

Kaasinen V, Rinne JO (2002) Functional imaging studies of dopamine system and cognition in normal aging and Parkinson's disease. Neurosci Biobehav Rev 26:785-793. Medline

Kleerekooper I, van Rooij SJH, van den Wildenberg WPM, de Leeuw M, Kahn RS, Vink M (2016) The effect of aging on fronto-striatal reactive and proactive inhibitory control. Neuroimage 132:51-58. CrossRef

Klotz U (2009) Pharmacokinetics and drug metabolism in the elderly. Drug Metab Rev 41:67-76. CrossRef Medline

Kramer AF, Humphrey DG, Larish JF, Logan GD, Strayer DL (1994) Aging and inhibition: beyond a unitary view of inhibitory processing in attention. Psychol Aging 9:491-512. CrossRef

Lieberman R, Corkin S, Spring B, Wurtman J, Growdon JH (1985) The effects of dietary neurotransmitter precursors on human behavior. American Journal of Clinical Nutrition, 42(2):366-370. Medline

Lindgren N, Xu ZQ, Herrera-Marschitz M, Haycock J, Hökfelt T, Fisone $G$ (2001) Dopamine $D(2)$ receptors regulate tyrosine hydroxylase activity and phosphorylation at Ser40 in rat striatum. Eur J Neurosci 13:773-780. CrossRef

Logan GD, Cowan WB (1984) On the ability to inhibit thought and action: a theory of an act of control. Psychol Rev 91:295-327. CrossRef

Lund TE, Norgaard MD, Rostrup E, Rowe JB, Paulson OB (2005) Motion or activity: their role in intra- and inter-subjects variation in fMRI. Neuroimage 26:960-964. CrossRef Medline

Magill R, Waters W, Bray G, Volaufova J, Smith S, Lieberman HR, McNevin N, Ryan D (2003) Effects of tyrosine, phentermine, caffeine D-amphetamine, and placebo on cognitive and motor performance deficits during sleep deprivation. Nutr Neurosci 6:237246. CrossRef Medline

Mahoney CR, Castellani J, Kramer FM, Young A, Lieberman HR (2007) Tyrosine supplementation mitigates working memory decrements during cold exposure. Physiol Behav 92:575-582. CrossRef

Martin W, Palmer M, Patlak C, Calne D (1989) Nigrostriatal function in humans studied with positron emission tomography. Ann Neurol 26:535-542. CrossRef Medline 
Michaud M, Balardy L, Moulis G, Gaudin C, Peyrot C, Vellas B, Cesari M, Nourhashemi F (2013) Proinflammatory cytokines, aging, and age-related diseases. J Am Med Dir Assoc 14:877-882. CrossRef Medline

Molinoff PB, Axelrod J (1971) Biochemistry of catecholamines. Annu Rev Biochem 40:465-500.

Moon S, Ranchet M, Akinwuntan A, Tant M, Carr D, Raji M, Devos H (2018) The impact of advanced age on driving safety in adults with medical conditions. Gerontology 63:291-299.

Moretti A, Carfagna N, Trunzo F (1987) Effect of aging on monoamines and their metabolites in the rat brain. Neurochem Res 12:1035-1039. Medline

Neri DF, Wiegmann D, Stanny RR, Shappell SA, McCardie A, McKay DL (1995) The effects of tyrosine on cognitive performance during extended wakefulness. Aviat Sp Environ Med 66:313-319.

Nicola S, Malenka R (1998) Modulation of synaptic transmission by dopamine and norepinephrine in ventral but not dorsal striatum. J Neurophysiol 79:1768-1776.

Ota M, Yasuno F, Ito H, Seki C, Nozaki S, Asada T, Suhara T (2006) Age-related decline of dopamine synthesis in the living human brain measured by positron emission tomography with L-[beta11C]DOPA. Life Sci 79:730-736.

Patton JH, Stanford MS, Barratt ES (1995) Factor structure of the Barratt impulsiveness scale. J Clin Psychol 51:768-774. CrossRef

Poser BA, Versluis MJ, Hoogduin JM, Norris DG (2006) BOLD contrast sensitivity enhancement and artifact reduction with multiecho EPI: parallel-acquired inhomogeneity-desensitized fMRI. Magn Reson Med 55:1227-1235. CrossRef

Rae CL, Nombela C, Rodríguez PV, Ye Z, Hughes LE, Jones PS, Ham T, Rittman T, Coyle-Gilchrist I, Regenthal R, Sahakian BJ, Barker RA, Robbins TW, Rowe JB (2016) Atomoxetine restores the response inhibition network in Parkinson's disease. Brain aww138.

Sawle G, Colebatch J, Shah A, Brooks D, Marsden C, Frackowiak RS (1990) Striatal function in normal aging: implications for Parkinson's disease. Ann Neurol 28:799-804. CrossRef Medline

Scally MC, Ulus I, Wurtman RJ (1977) Brain tyrosine level controls striatal dopamine synthesis in haloperidol-treated rats. Neural Transm 41:1-6. CrossRef

Schippers MC, Schetters D, De Vries TJ, Pattij T (2016) Differential effects of the pharmacological stressor yohimbine on impulsive decision making and response inhibition. Psychopharmacology (Berl) 233:2775-2785.

Schmand B, Bakker D, Saan R, Louman J (1991) The Dutch reading test for adults. Gerontol Geriatr 22:15-19.

Shurtleff D, Thomas JR, Schrot J, Kowalski K, Harford R (1994) Tyrosine reverses a cold-induced working memory deficit in humans. Pharmacol Biochem Behav 47:935-941. CrossRef

Steenbergen L, Sellaro R, Hommel B, Colzato LS (2015) Tyrosine promotes cognitive flexibility: evidence from proactive vs. reactive control during task switching performance. Neuropsychologia 69: 50-55. CrossRef

Stroop J (1935) Studies of interference in serial verbal reactions. J Exp Psychol 18:643-662. CrossRef
Thomas JR, Lockwood PA, Singh A, Deuster PA (1999) Tyrosine improves working memory in a multitasking environment. Pharmacol Biochem Behav 64:495-500. CrossRef

Tombaugh TN, Kozak J, Rees L (1999) Normative data stratified by age and education for two measures of verbal fluency: FAS and animal naming. Arch Clin Neuropsychol 14:167-177. Medline

Turner DC, Robbins TW, Clark L, Aron AR, Dowson J, Sahakian BJ (2003) Relative lack of cognitive effects of methylphenidate in elderly male volunteers. Psychopharmacology (Berl) 168:455-464. CrossRef

Tzourio-Mazoyer N, Landeau B, Papathanassiou D, Crivello F, Etard O, Delcroix N, Mazoyer B, Joliot M (2002) Automated anatomical labeling of activations in SPM using a macroscopic anatomical parcellation of the MNI MRI single-subject brain. Neuroimage 15:273-289. CrossRef

Uttl B (2002) North American adult reading test: age norms, reliability, and validity. J Clin Exp Neuropsychol 24:1123-1137. CrossRef

van Belle J, Vink M, Durston S, Zandbelt BB (2014) Common and unique neural networks for proactive and reactive response inhibition revealed by independent component analysis of functional MRI data. Neurolmage, 103C, 65-74. CrossRef

van de Laar MC, van den Wildenberg WPM, van Boxtel GJM, van der Molen MW (2011) Lifespan changes in global and selective stopping and performance adjustments. Front Psychol 2:357. CrossRef

van de Rest O, Bloemendaal M, De Heus R, Aarts E (2017) Dosedependent effects of oral tyrosine administration on plasma tyrosine levels and cognition in aging. Nutrients 9. CrossRef

Verbruggen F, Logan GD (2009) Models of response inhibition in the stop-signal and stop-change paradigms. Neurosci Biobehav Rev 33:647-661.

Wang Y, Chan GL, Holden JE, Dobko T, Mak E, Schulzer M, Huser JM, Snow BJ, Ruth TJ, Calne DB, Stoessl AJ (1998) Agedependent decline of dopamine D1 receptors in human brain: a PET study. Synapse 30:56-61. CrossRef Medline

Wechsler DA (1997) Wechsler adult intelligence scale, Ed 4. San Antonio: The Psychological Corporation.

Wilson B, Cockburn J, Baddeley A (1985) The Rivermead behavioral memory test. Hampshire: Thames Valley Test Company.

World Health Organization (1985) Energy and protein requirements. Report of a joint $\mathrm{FAO} / \mathrm{WHO} / \mathrm{UNU}$ expert consultation. World Health Organ Tech Rep Ser 724:1-206.

Zandbelt BB, Vink M (2010) On the role of the striatum in response inhibition. PLoS One 5:e13848.

Zandbelt BB, Bloemendaal M, Hoogendam JM, Kahn RS, Vink M (2013) Transcranial magnetic stimulation and functional MRI reveal cortical and subcortical interactions during stop-signal response inhibition. J Cogn Neurosci 25:157-174. CrossRef

Zizza CA, Ellison KJ, Wernette CM (2009) Total water intakes of community-living middle-old and oldest-old adults. J Gerontol A Biol Sci Med Sci 64:481-486. CrossRef 